\title{
Identification and Characterization of ANAC042, a Transcription Factor Family Gene Involved in the Regulation of Camalexin Biosynthesis in Arabidopsis
}

\author{
Hirohisa Saga, ${ }^{1}$ Takumi Ogawa, ${ }^{1}$ Kosuke Kai, ${ }^{1}$ Hideyuki Suzuki, ${ }^{2}$ Yoshiyuki Ogata, ${ }^{2}$ Nozomu Sakurai, ${ }^{2}$ \\ Daisuke Shibata, ${ }^{2}$ and Daisaku Ohta ${ }^{1}$ \\ ${ }^{1}$ Graduate School of Life and Environmental Sciences, Osaka Prefecture University, Sakai, Osaka 599-8531, Japan; ${ }^{2}$ Kazusa \\ DNA Research Institute, Kisarazu, Chiba 292-0818, Japan
}

Submitted 21 September 2011. Accepted 12 January 2012.

Camalexin is the major phytoalexin in Arabidopsis. An almost complete set of camalexin biosynthetic enzymes have been elucidated but only limited information is available regarding molecular mechanisms regulating camalexin biosynthesis. Here, we demonstrate that $A N A C 042$, a member of the NAM, ATAF1/2, and CUC2 (NAC) transcription factor family genes, is involved in camalexin biosynthesis induction. T-DNA insertion mutants of $A N A C 042$ failed to accumulate camalexin at the levels achieved in the wild type, and were highly susceptible to Alternaria brassicicola infection. The camalexin biosynthetic genes CYP71A12, $C Y P 71 A 13$, and $C Y P 71 B 15 / P A D 3$ were not fully induced in the mutants, indicating that the camalexin defects were at least partly a result of reduced expression levels of these P450 genes. $\beta$-Glucuronidase (GUS)-reporter assays demonstrated tissue-specific induction of $A N A C 042$ in response to differential pathogen infections. Bacterial flagellin (Flg22) induced $A N A C 042$ expression in the root-elongation zone, the camalexin biosynthetic site, and the induction was abolished in the presence of either a general kinase inhibitor (K252a), a $\mathrm{Ca}^{2+}$-chelator (BAPTA), or methyl jasmonate. The GUS-reporter assay revealed repression of the Flg22-dependent $A N A C 042$ expression in the ethylene-insensitive ein2-1 background but not in sid2-2 plants defective for salicylic acid biosynthesis. We discuss ANAC042 as a key transcription factor involved in previously unknown regulatory mechanisms to induce phytoalexin biosynthesis in Arabidopsis.

Plants produce a myriad of secondary metabolites as the primary defense strategy to cope with ever-changing biotic and abiotic stress conditions. Individual plant species have evolved diverse complements of defense compounds. Such defense

Current address for K. Kai: SYSMEX Corporation, Chuo-ku, Kobe, 6510073, Japan.

Current address for Y. Ogata: RIKEN Yokohama Institute, Yokohama 230-0045, Japan.

Corresponding author: Daisaku Ohta; Telephone: +81-72-254-9409; Fax: +81-72-254-9409; E-mail: ohtad2g30490@bioinfo.osakafu-u.ac.jp

* The $\boldsymbol{e}$-Xtra logo stands for "electronic extra" and indicates that nine supplementary figures and three supplementary tables are published online and that Figures 2 and 4 appear in color online. compounds are often classified into two classes, phytoalexins and phytoanticipins. In general, phytoalexins are synthesized in response to the onset of stress cues, and phytoanticipins are preformed and stored within specialized organs or cells (e.g., tricomes, oil glands, and myrosin cells), invoking chemical defense systems when necessary. The biosynthetic precursors of these secondary metabolites are derived from primary metabolic pathways and, therefore, such secondary metabolic activities should be coordinated, so as not to threaten normal developmental or growth processes. Thus, activities of independent secondary pathways are controlled to synthesize the correct metabolites in temporally and spatially appropriate manners. Recent molecular genetics and genomics studies using the model plant species Arabidopsis thaliana have provided deep insights into regulatory mechanisms controlling secondary metabolic pathways, particularly focusing on the biosyntheses of glucosinolates (GLS) (Grubb and Abel 2006; Halkier and Gershenzon 2006; Sønderby et al. 2010).

Camalexin, an indolic secondary metabolite, is the major phytoalexin produced by A. thaliana (Ausubel et al. 1995; Glawischnig 2007). Camalexin biosynthesis is induced in response to infection by bacterial pathogens, such as Pseudomonas syringae and Erwinia carotovora, and also necrotrophic fungi, including Alternaria brassicicola and Botrytis cinerea, as well as other exogenous stress cues, including herbicides, heavy metal ions, and UV-B irradiation. The biosynthetic pathway intermediates as well as the genes responsible have been characterized extensively using camalexin-deficient mutants and radioisotope-labeling studies with potential biosynthetic precursors (Fig. 1). The first step of camalexin biosynthesis is catalyzed by the cytochrome P450 enzymes CYP79B2 and CYP79B3, converting Trp to indole-3-acetaldoxime (IAOx), a common biosynthetic precursor of indolic glucosinolates, the phytohormone auxin (indole-3-acetic acid), and camalexin (Glawischnig et al. 2004; Hull et al. 2000; Mikkelsen et al. 2000). In the camalexin biosynthetic pathway, IAOx is further converted to indole-3-acetonitrile (IAN) by a different P450 enzyme, CYP71A13 (Nafisi et al. 2007) and CYP71A12 (Millet et al. 2010). Recently, it was reported that glutathione (GSH) is conjugated to IAN by glutathione $S$-transferases, including GSTF6, to form GSH(IAN), an intermediate in camalexin biosynthesis (Su et al. 2011). Su and associates (2011) proposed that GSH(IAN) is hydrolyzed by the steps involving either $\gamma$ glutamyl transpeptidases, GGT1 and GGT2, or a phytochelatin synthase, PCS1, yielding Cys(IAN). Geu-Flores and associates 
(2011) demonstrated the involvement of $\gamma$-glutamyl peptidases (GGP1 and GGP3) in the processing of GSH(IAN) and glucosinolate-related GSH conjugates in camalexin biosynthesis and glucosinolate biosynthesis, respectively. The pathway end product, camalexin, is formed by the two-step reaction from Cys(IAN) via dihydrocamalexic acid catalyzed by a cytochrome P450 enzyme, CYP71B15/PAD3 (Böttcher et al. 2009; Schuhegger et al. 2006).

The involvement of a transcription factor, WRKY33, and mitogen-activated protein (MAP) kinase cascade is well characterized in the induction of camalexin biosynthesis. Mutant plants with defective WRKY33 were highly susceptible to infection by $B$. cinerea and $A$. brassicicola, and its overexpression resulted in acquisition of increased resistance (Zheng et al. 2006). It was reported that WRKY33 bound the promoter regions of $C Y P 71 B 15 / P A D 3$ in response to $P$. syringae infection (Qiu et al. 2008). In response to challenges such as $P$. syringae infection and the bacterial elicitor flagellin, MPK4 is activated to phosphorylate MKS1, releasing WRKY33 from the MKS1/ WRKY33 complex, and WRKY33 targets the promoter of $C Y P 71 B 15$, thereby stimulating camalexin biosynthesis (Qiu et al. 2008). On the other hand, WRKY33 is phosphorylated by MPK3/MPK6 in the induction cascade of camalexin biosynthesis in Arabidopsis seedlings in response to $B$. cinerea infection (Mao et al. 2011). It is likely that infection signals of different pathogens are transmitted through independent MAP cascades converging to WRKY33 activation, leading to the induction of camalexin biosynthesis.
Here, we characterize a transcription factor gene, ANACO42, involved in the regulation of camalexin biosynthesis in Arabidopsis. ANAC042 belongs to a plant-specific NAM, ATAF1/2, and CUC2 (NAC) transcription factor protein family, which is involved in a number of biological processes such as development, senescence, morphogenesis, and stress signal transduction pathways (Olsen et al. 2005b). We discuss possible signaling networks coordinated to respond to variable stress conditions leading to the production of camalexin.

\section{RESULTS}

\section{Identification of $\mathrm{ANAC042}$ as a possible regulator of camalexin biosynthesis.}

Camalexin biosynthesis is induced by the infection of microbial pathogens and abiotic stresses such as herbicide application and heavy metal treatment (Glawischnig 2006, 2007). With the aim of identifying positive regulators of camalexin biosynthesis in Arabidopsis, we listed putative transcription factor genes strongly induced during the time course of $\mathrm{AgNO}_{3}$ treatment (Table 1) from a transcriptome analysis (Supplementary Table S1). Among the listed transcription factor genes, a possible correlation with camalexin biosynthesis was suggested only for ANACO42 by the gene coexpression analyses using ATTED-II and KAGIANA. Detailed coexpression network analyses was performed with Arabidopsis microarray datasets (3,654 assays of ATH1 format; Affymetrix, Santa Clara, CA, U.S.A.) using the Confeito algorithm (Ogata et al. 2009) (Sup-

Table 1. Induction of transcription factor genes in Arabidopsis plants during the treatment with $\mathrm{AgNO}_{3}{ }^{\mathrm{a}}$

\begin{tabular}{|c|c|c|c|c|}
\hline \multirow[b]{2}{*}{ Locus } & \multirow[b]{2}{*}{ Symbol } & \multicolumn{2}{|c|}{ Fold change by $\mathrm{AgNO}_{3}$} & \multirow[b]{2}{*}{ Functional annotation } \\
\hline & & $48 \mathrm{~h}$ & $72 \mathrm{~h}$ & \\
\hline At2g43000 & ANAC042 & 19.74 & 46.58 & Unknown \\
\hline At1g61110 & ANAC025 & 18.63 & 18.68 & Unknown \\
\hline At5g46350 & AtWRKY8 & 11.61 & 19.58 & Basal defense \\
\hline At2g 40740 & AtWRKY55 & 14.50 & 23.52 & Unknown \\
\hline At1g66600 & AtWRKY63 & 25.51 & 27.06 & Drought tolerance \\
\hline At1g29860 & AtWRKY71 & 10.71 & 24.15 & Unknown \\
\hline At3g27810 & AtMYB21 & 14.16 & 19.96 & Stamen development \\
\hline At3g48920 & AtMYB45 & 10.37 & 14.80 & Unknown \\
\hline At1g56160 & AtMYB72 & 20.65 & 11.78 & Systemic resistance \\
\hline At1g56650 & AtMYB75 & 38.97 & 13.77 & Anthocyanin metabolism \\
\hline At4g13480 & AtMYB79 & 18.79 & 19.86 & Unknown \\
\hline Atlg66370 & AtMYB113 & 26.66 & 16.12 & Anthocyanin metabolism \\
\hline At3g56970 & bHLH38 & 219.56 & 168.42 & Iron assimilation \\
\hline At3g56980 & bHLH39 & 100.60 & 86.90 & Iron assimilation \\
\hline At2g41240 & bHLH100 & 373.74 & 260.09 & Iron assimilation \\
\hline At5g04150 & bHLH101 & 25.16 & 21.16 & Iron assimilation \\
\hline
\end{tabular}

${ }^{a}$ Wild-type Arabidopsis plants were harvested at 48 and $72 \mathrm{~h}$ after the treatment with $0.1 \mathrm{mM} \mathrm{AgNO}$. Transcription factor genes upregulated more than 10 fold were listed from a transcriptomics analysis. Fold changes were the average values calculated from triplicate experiments.

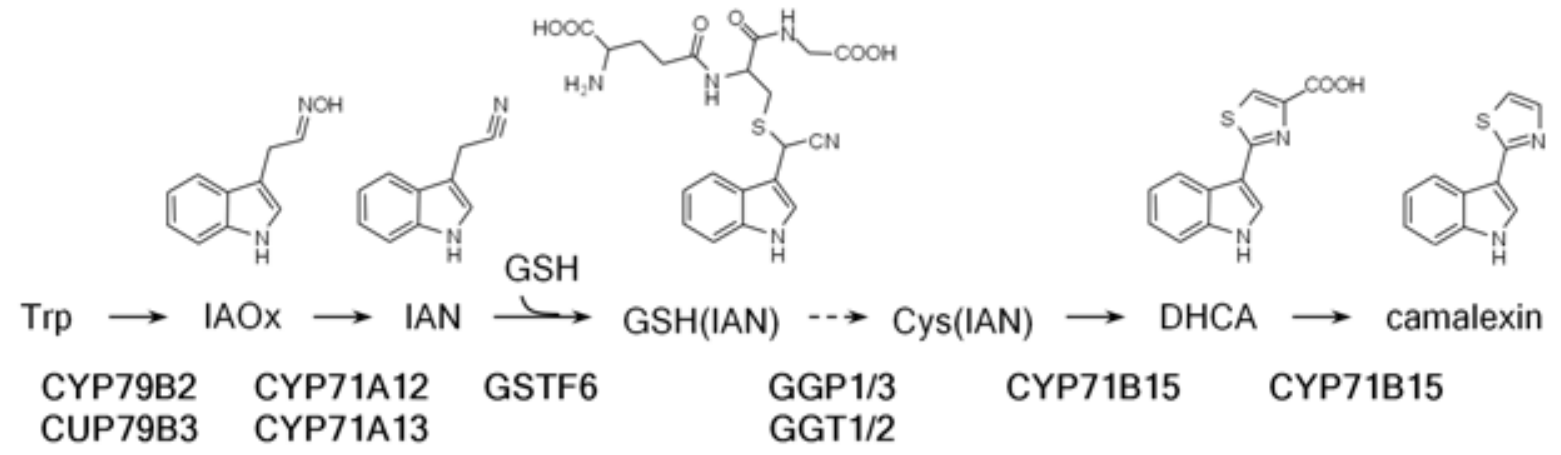

Fig. 1. Camalexin biosynthetic pathway. Camalexin is synthesized from Trp, which is converted to indole-3-acetaldoxime (IAOx) by CYP79B2 and CYP79B3. IAOx serves as the precursor of indolic glucosinolate and is the substrate of CYP71A13 and CYP71A12, yielding indole-3-acetonitrile (IAN). IAN is conjugated with glutathione (GSH) by glutathione $S$-transferases, including GSTF6 to form GSH(IAN). GGP1/3 and GGT1/2 are involved in the formation of Cys(IAN). The last biosynthetic step is catalyzed by CYP71B15/PAD3 via the formation of dihydrocamalexic acid (DHCA) from Cys(IAN). 


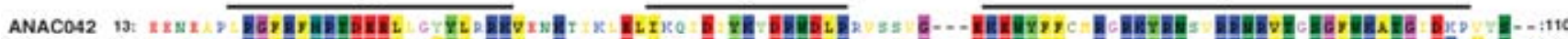

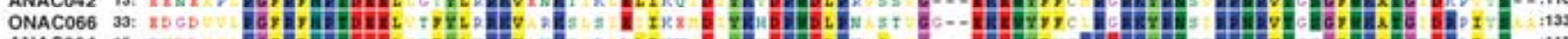

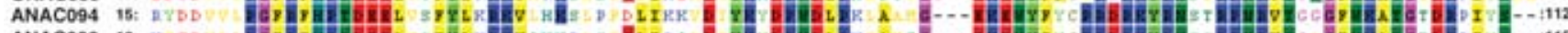

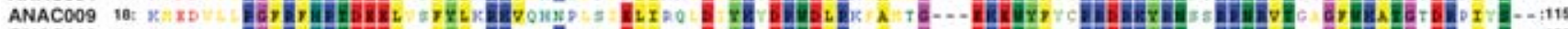

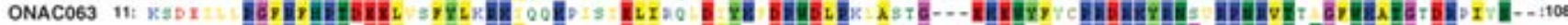
ONAC053 25: 9 HD ANAC035 46: HDHO ONAC075 3is

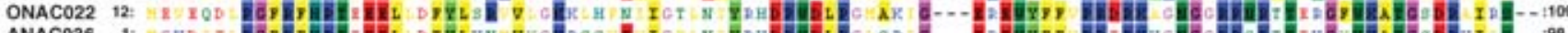

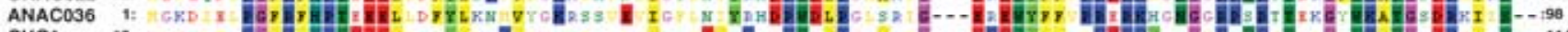

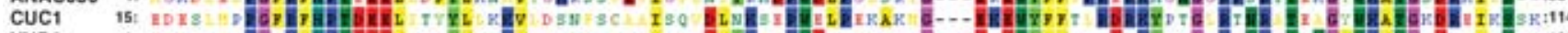

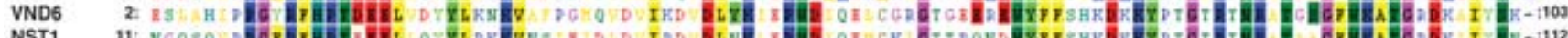

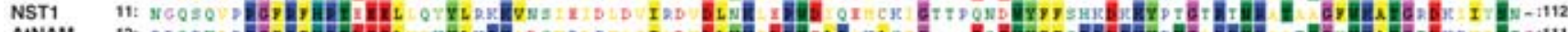

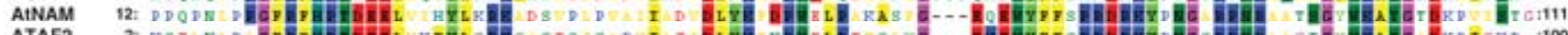

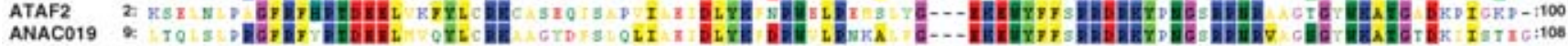

d

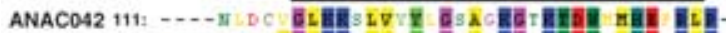

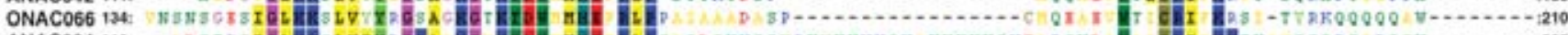
ANACO94 113: - D DSTRCICLE

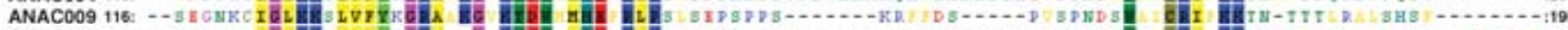

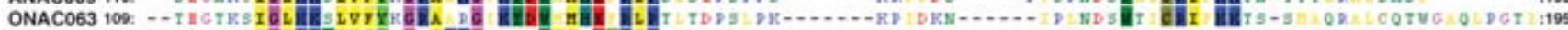

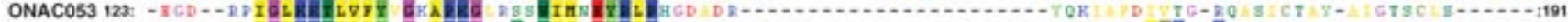

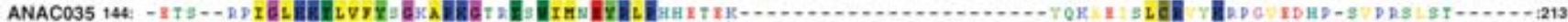

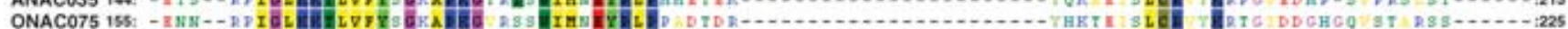

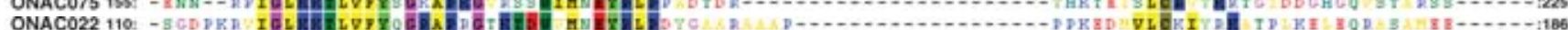

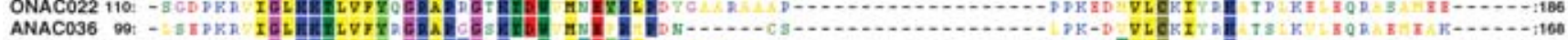

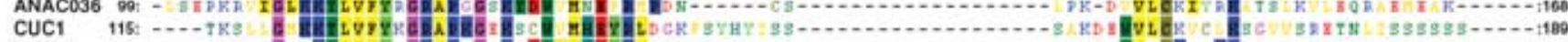

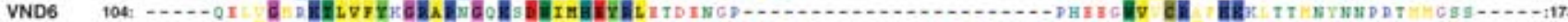

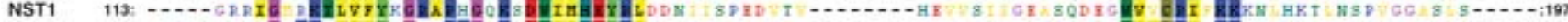

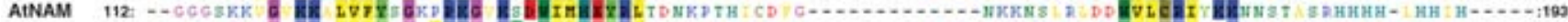
ATAF2 101: - N. ANAC019 100: ..... O D
B
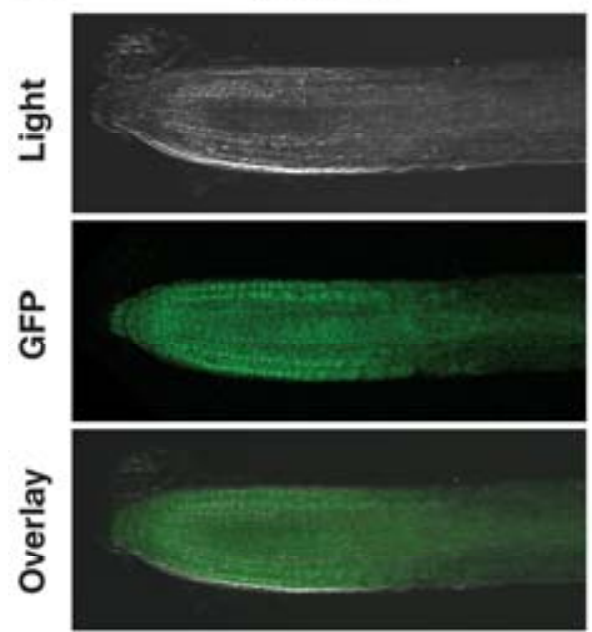

C
35S:ANAC042-GFP
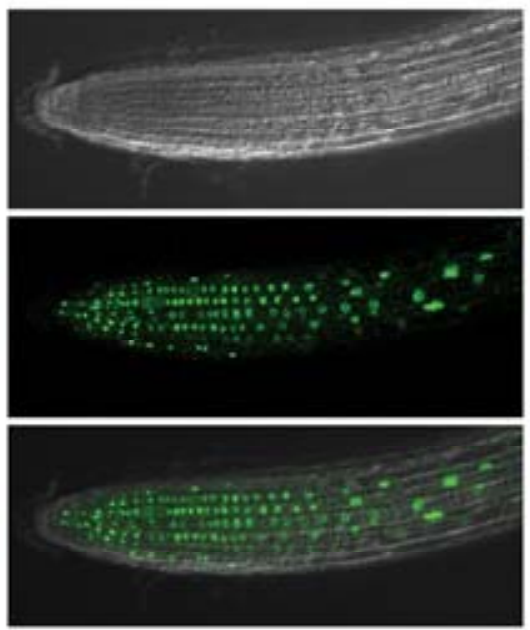

ANAC009

ONAC063

ANAC094

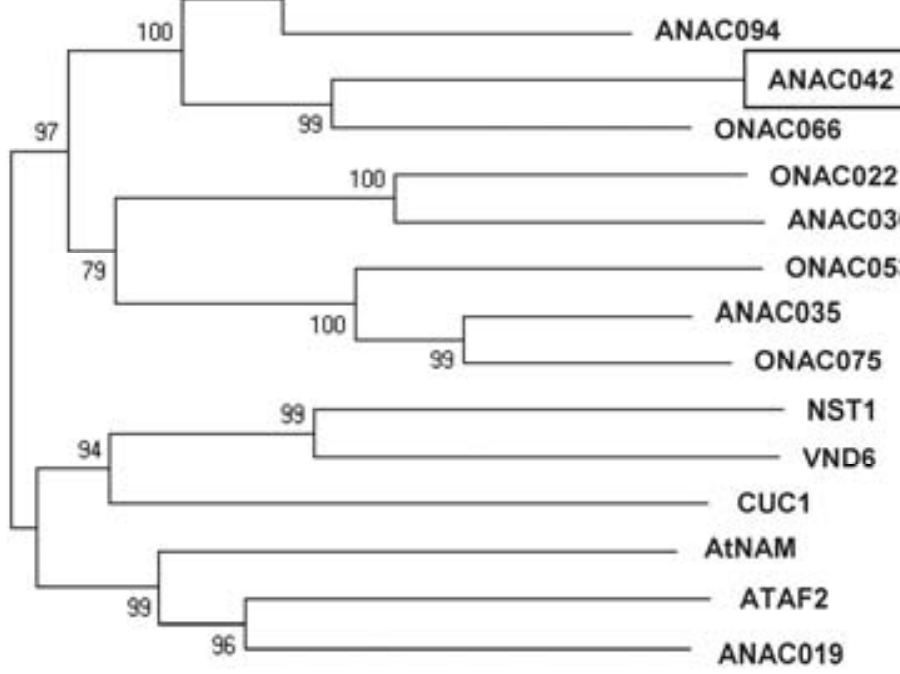

35S:ANAC042-GFP
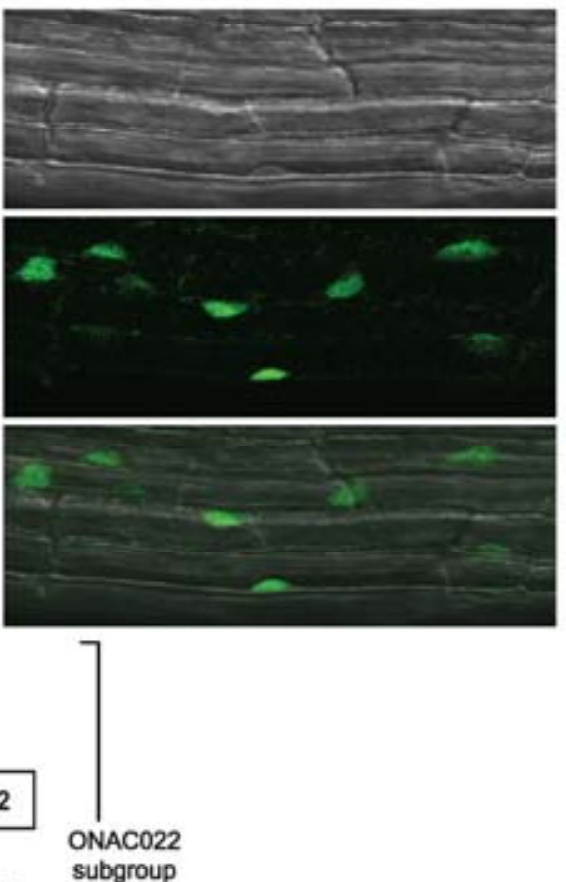

subgroup 
plementary Fig. S1). ANAC042 was found within an expression module containing camalexin biosynthetic genes, including CYP71A12, CYP71A13, and CYP71B15/PAD3, and this coexpression module closely correlated to another module comprising MYB51, Botrytis-induced protein kinase 1 (BIK1), and WRKY25 related to plant defense responses. MYB51 is a positive regulator of indolic glucosinolates biosynthesis, acting together with $M Y B 122$ and ATR1/MYB34 (Celenza et al. 2005; Gigolashvili et al. 2007). The $B I K 1$ gene serves as a positive and negative regulator in the resistance mechanisms exerted toward infection by necrotrophic fungi and bacterial infection with $P$. syringae, respectively (Veronese et al. 2006). BIK1 is a leucine-rich repeat-receptor-like kinase involved in the microbeassociated molecular pattern (MAMP) signal transduction cascades by forming a complex with the flagellin receptor FLS2 (Lu et al. 2010). These observations prompted us to clarify whether ANACO42 might function in disease resistance through transcriptional regulation of camalexin biosynthetic genes.

ANAC042 was predicted to encode a protein of 275 amino acids belonging to a plant-specific NAC transcription factor protein family, which is involved in a number of biological processes such as development, senescence, morphogenesis, and stress signal transduction pathways (Olsen et al. 2005b). Sequence comparison (Fig. 2A) revealed that the ANAC042 primary structure contains five NAC-related DNA-binding domains in the N-terminal region. In addition, the ANAC042 contains essential amino acid residues for the interaction with DNA (Olsen et al. 2005a) and possible nuclear localization signal sequence (Kikuchi et al. 2000; Olsen et al. 2005a). Ooka and associates (2003) analyzed NAC sequences (105 genes from Arabidopsis and 75 genes from rice) and classified them into 18 subgroups comparing the deduced amino acid sequences. ANAC042 belongs to the ONAC022 subfamily (Ooka et al. 2003), which includes six Arabidopsis NAC proteins (Fig. 2C). A subcellular localization study indicated that an ANAC042-GFP (green fluorescent protein) fusion protein was primarily present within the nuclei of Arabidopsis root cells (Fig. 2B). These observations support the notion that ANAC042 could function as a transcription factor.

The expression of $A N A C 042$ in wild-type plants was strongly induced by $\mathrm{AgNO}_{3}$ treatment, and the ANACO42 transcript accumulation time course was very similar to those of the induction of camalexin biosynthetic genes $C Y P 79 B 2, C Y P 71 A 12$, and $C Y P 71 B 15$ (Fig. 3A). Upon infection with a compatible strain of $P$. syringae pv. tomato, DC3000, the ANAC042 transcript level in rosette leaves transiently increased, with the peak occurring at $2 \mathrm{~h}$, and then decreased within $6 \mathrm{~h}$ post infection (Fig. 3B). In contrast, ANACO42 transcript accumulation continued to increase (Fig. 3B) after infection by an incompatible $P$. syringae strain (avrRPT2) carrying the avirulence gene avrRPT2, a $P$. syringae type III effector (Whalen et al. 1991). In the plants infected by avrRPT2, the transcript levels of CYP71A12 and CYP71B15 followed a time course similar to that observed for ANACO42 induction (Fig. 3B), and these gene transcript levels were reduced at $6 \mathrm{~h}$ after infection with the compatible strain DC3000.

\section{Involvement of $A N A C 042$ in the induction of camalexin biosynthesis.}

The possible involvement of ANACO42 in the induction of camalexin biosynthesis was studied using two independent Arabidopsis lines, anac042-1 and anac042-2, carrying T-DNA insertion events within the ANACO42 gene. The T-DNA inser-

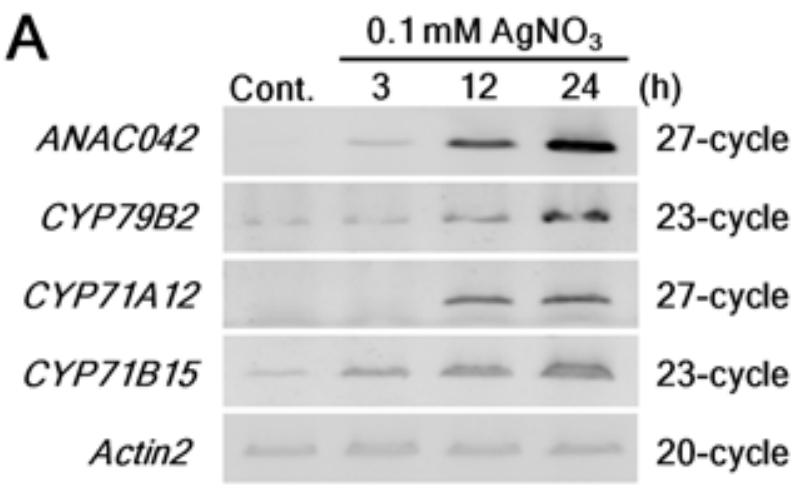

B

\section{Pst/DC3000 Pst/avrRPT2}

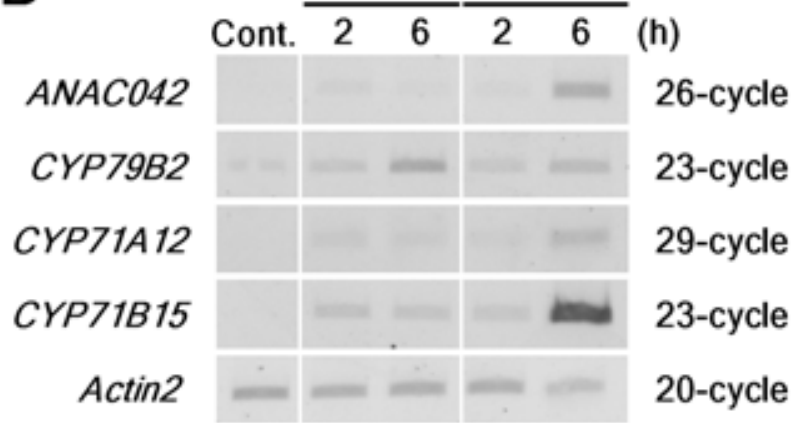

Fig. 3. Induction of ANACO42 in Arabidopsis. ANACO42 transcript levels in Arabidopsis Col-0 wild-type plants were determined by semiquantitative reverse-transcription polymerase chain reaction (PCR). A, Seedlings (1 week old) germinated on GM agar plates were transferred to GM liquid culture medium and grown for a further 2 weeks. Plants were then treated with $0.1 \mathrm{mM} \mathrm{AgNO}_{3}$ and sampled after $24 \mathrm{~h}$ of treatment. PCR reaction cycles are indicated to the right of the panel. B, Plants were grown for 30 days in soil. Rosette leaves were infected by infiltration by a bacterial suspension $\left(1 \times 10^{7} \mathrm{CFU} / \mathrm{ml}\right.$ in $\left.10 \mathrm{mM} \mathrm{MgCl} 2\right)$ of either Pseudomonas syringae pv. tomato DC3000 (Pst/DC3000) or Pst/DC3000 carrying the avirulence gene avrRPT2 (Pst/avrRPT2). Infected leaves were sampled after 2 and $6 \mathrm{~h}$ of the infection time course. PCR reaction cycles are indicated to the right of the panel. Control (Cont.) is a mock treatment with $10 \mathrm{mM}$ $\mathrm{MgCl}_{2}$.

Fig. 2. Characterization of the ANAC042 protein sequence. A, Alignment of the N-terminal regions of NAM, ATAF1/2, and CUC2 (NAC) proteins. Putative N-terminal NAC domains (from a through e) are indicated by lines above the sequences. The putative nuclear localization sequences (Kikuchi et al. 2000; Olsen et al. 2005a) are underlined. Essential amino acid residues for the interaction with DNA (Olsen et al. 2005a) are marked by asterisks under the sequences. GenBank accession numbers are as follows: ANAC042, NP_181828; ANAC094, NP_198798; ANAC009, NP_174009; ANAC035, NP_565284; ANAC036, NP_565404; CUC1, NP_188135; VND6, NP_201044; NST1, NP_182200; AtNAM, NP_175696; ATAF2, NP_680161; ANAC019, NP_175697; ONAC066, NP_001051438; ONAC063, NP_001061889; ONAC053, NP_001060841; ONAC075, NP_001045038; and ONAC022, NP_001048872. B, Nuclear localization of ANAC042-GFP (green fluorescent protein) fusion protein. Either GFP or ANAC042-GFP fusion protein was expressed under the control of Cauliflower mosaic virus 35S promoter in Arabidopsis plants (35S:GFP, 35S:ANAC042-GFP). Roots of transgenic plants were observed and photographed using a laser-scanning confocal microscope. C, Phylogenetic tree of NAC proteins. MEGA5 (Tamura et al. 2011 ) was used for phylogenetic tree construction. Protein sequences were multi-aligned using ClustalW program in MEGA5. This alignment was used for a bootstrap test (1,000 replicates) for phylogeny using the neighbor-joining method (Saitou and Nei 1987). The scale bar shows 0.05 changes, and bootstrap support values ( $>70 \%$ ) are shown at the nodes. 
tions of anac042-1 and anac042-2 were located within the second intron (Supplementary Fig. S2), and only faint levels of ANAC042 transcripts were detected in these mutant plants (Supplementary Table S2). Although these mutant plants displayed no visible abnormality throughout their life cycle, it is possible that functional transcripts might still be present in these mutant lines. The camalexin levels in the shoots of Col- 0 wild-type plants were quickly elevated within $24 \mathrm{~h}$ of $\mathrm{AgNO}_{3}$ treatment, while camalexin accumulation in anac042-1 and anac042-2 was approximately 40 and $31 \%$ that of the wildtype plants, respectively (Fig. 4A). Decreased camalexin induction in the mutant lines were also observed in infection studies with A. brassicicola (Fig. 4B), and anac042-1 and anac042-2 lines were highly susceptible to infection by $A$. brassicicola (Fig. 4D). Furthermore, camalexin induction by acifluorfen application (Fig. 4C) was greatly reduced in anac042-1 and anac042-2 plants. Acifluorfen is a herbicidal compound that inhibits protoporphyrinogen oxidase, leading to the generation
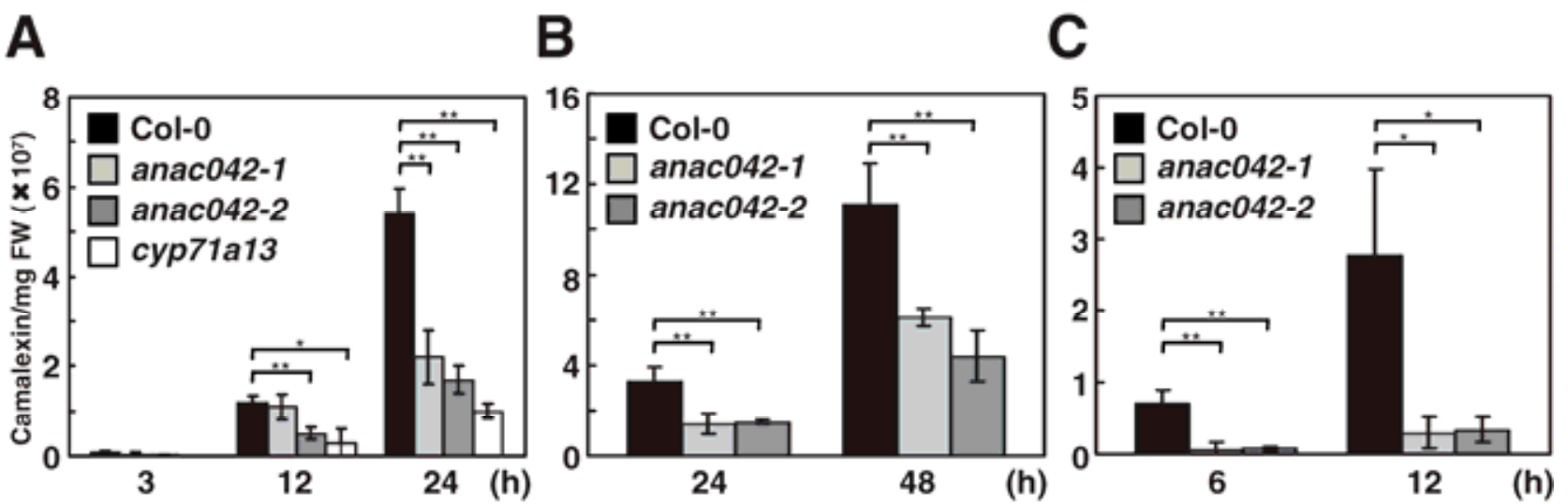

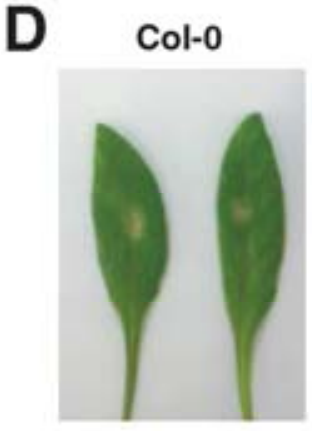

cyp71a13

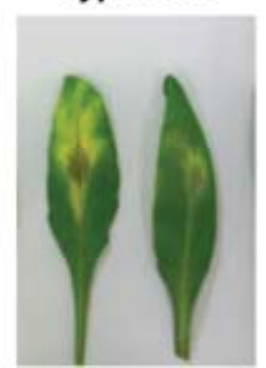

anac042-1

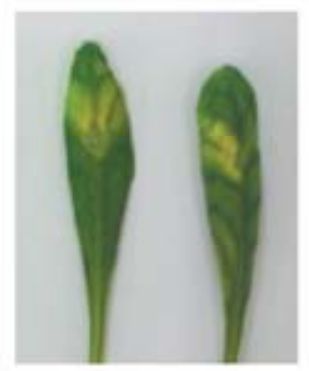

anac042-2

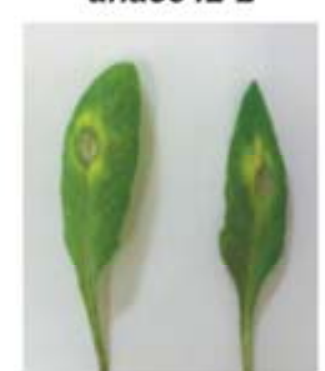

E

Col-0 nac042-1 \#9

\#11

\#16

ANAC042

28-cycle

Actin2

20-cycle
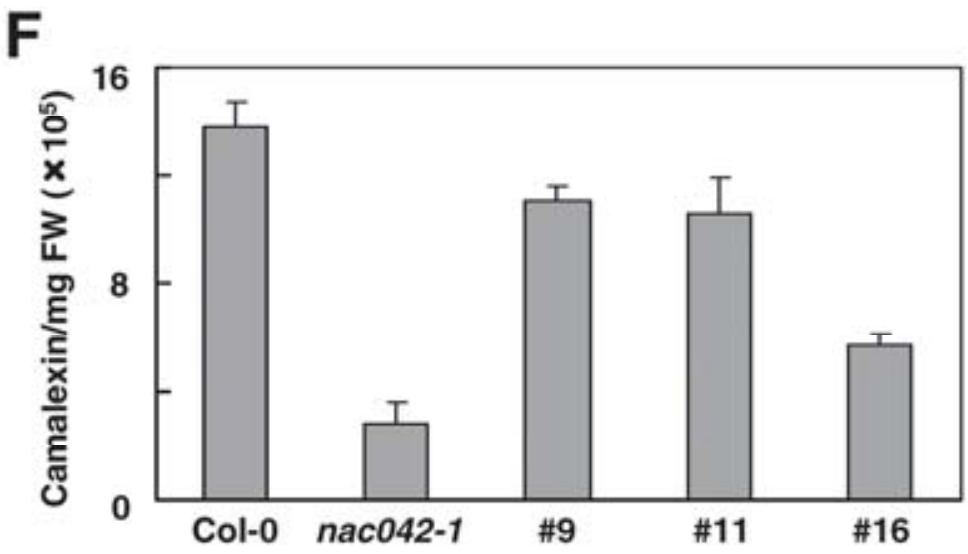

Fig. 4. Relative comparison of camalexin levels in response to $\mathrm{AgNO}_{3}$ and acifluorfen treatment and Alternaria brassicicola infection. Camalexin accumulation levels were compared using 6-fluoroindole-3-carboxaldehyde as the reference compound. Camalexin was identified by FT-ICR/MS (Fourier-transform ion cyclotron resonance mass spectrometry). A, Camalexin induction by $\mathrm{AgNO}_{3}$. Plants (Col-0 wild-type, anac042-1, anac042-2, and cyp 71a13) were grown for 50 days in soil. Rosette leaves were sprayed with $5 \mathrm{mM} \mathrm{AgNO}_{3}$ in $0.02 \%$ Silwet L-77. Leaves were sampled in triplicate at 3, 12, and $24 \mathrm{~h}$ after the treatment; * and ** indicate $P$ value $<0.05$ and 0.01 , respectively, one-way analysis of variance (ANOVA) with Dunnet's post-hoc test. B, Camalexin induction by $A$. brassicicola infection. Drops of spore suspension $(10 \mu \mathrm{l})$ of A. brassicicola $\left(5 \times 10^{5}\right.$ spores $\left./ \mathrm{ml}\right)$ were applied to each rosette leaf of 30 -dayold plants of Col-0 wild-type, anac042-1, and anac042-2 plants. Leaves were sampled in triplicate 24 and $48 \mathrm{~h}$ after the infection; * and ** indicate $P$ value $<$ 0.05 and 0.01, respectively, one-way ANOVA with Dunnet's post-hoc test. C, Camalexin induction by acifluorfen application. Rosette leaves of 30-day-old plants of Col-0 wild-type, anac042-1, and anac042-2 plants were sprayed with $0.1 \mathrm{mM}$ acifluorfen in $0.05 \%$ Silwet L-77. Leaves were sampled in triplicate 6 and $12 \mathrm{~h}$ after herbicide application. Plant extracts were separated by high-performance liquid chromatography and the peaks were detected using a fluorometer (excitation at $318 \mathrm{~nm}$, emission at $370 \mathrm{~nm}$ ); * and ** indicate $P$ value $<0.05$ and 0.01 , respectively, one-way ANOVA with Dunnet's post-hoc test. D, Susceptibility of anac042-1 and anac042-2 plants to infection by the necrotrophic fungus A. brassicicola. Plants (Col-0 wild-type, anac042-1, anac042-2, and cyp71a13) were grown for 50 days in soil, and the rosette leaves were infected with spores from A. brassicicola. Fungal spores were suspended in distilled water for inoculation. Drops of $100-\mu l$ spore suspension $\left(5 \times 10^{5}\right.$ spores $\left./ \mathrm{ml}\right)$ were applied to each leaf. Leaves were photographed $72 \mathrm{~h}$ after inoculation. E, Genetic complementation of the ANAC042 T-DNA insertion line. Three independent complementation lines (numbers 9, 11, and 16) derived from anac042-1 were characterized in terms of camalexin biosynthesis. Seed were germinated on GM agar plates, and 1-week-old seedlings were transferred to GM liquid medium. Two weeks after germination, the plants were treated for $72 \mathrm{~h}$ with $0.1 \mathrm{mM} \mathrm{AgNO}$. ANAC042 induction levels were determined by semiquantitative reverse-transcription polymerase chain reaction (RT-PCR). F, Genetic complementation of the ANAC042 T-DNA insertion line. Camalexin contents were determined using the same plants as used for the RT-PCR analyses shown in E. 
of reactive oxygen species (ROS) (Witkowski and Halling 1989), suggesting that ANACO42 might be involved in an ROSdependent signaling pathway to induce camalexin biosynthesis.

To confirm whether the defects in camalexin biosynthesis could be ascribed to the T-DNA insertion events, the anac0421 line was subjected to genetic complementation using a genomic fragment containing the entire coding sequence of ANAC042 together with a 1.5 -kb upstream promoter region. ANAC042 transcript accumulation and camalexin induction were recovered to the levels almost comparable with those of wild-type plants (complementation line numbers 9 and 11) (Fig. 4E and F). Another complementation line, number 16, accumulated ANACO42 transcript at a lower level compared with line numbers 9 and 11, representing partial complementation of camalexin induction (Fig. 4E and F). These results indicated that the T-DNA insertions were the cause for the reduced levels of camalexin accumulation of the mutant plants.

In the roots of anac042-1 and anac042-2 plants treated with $\mathrm{AgNO}_{3}, C Y P 71 A 12, C Y P 71 A 13$, and $C Y P 71 B 15 / P A D 3$ expression levels were significantly lower than those in wild-type roots (Fig. 5). In contrast, $C Y P 79 B 2$ and $C Y P 79 B 3$ expression levels were unaffected in mutant plant roots treated with $\mathrm{AgNO}_{3}$. Under our experimental conditions, the ANACO42 transcript levels in the roots of anac042-1 and anac042-2 plants decreased to almost comparable levels, while the P450 gene transcript levels were likely to be more strongly affected in anac042-1 plants. To sum up these results, ANAC042 could be involved in camalexin biosynthesis through regulation of the camalexin biosynthetic P450 genes functioning at downstream steps of IAOx production involving CYP79B2 and CYP79B3 activity.

\section{Regulation of $\mathrm{ANAC042}$ expression.}

For precise analyses of $A N A C 042$ induction, we generated six independent transgenic lines (ANAC042pro:GUS) expressing the $\beta$-glucuronidase $(G U S)$ reporter gene under the control of the putative ANAC042 promoter $1.5 \mathrm{~kb}$ in length from the 5 '-upstream region (Supplementary Fig. S3). Further experiments were performed using one of these ANAC042pro:GUS lines exhibiting reproducible GUS-staining patterns. Under normal growth conditions, faint GUS staining was observed in the region just below the hypoctyl-root junction; the region was stained with 3,3'-diaminobenzidine (DAB) for $\mathrm{H}_{2} \mathrm{O}_{2}$ generation and as small spots in the region of the shoot apical meristem (SAM) (Fig. 6A and B). No GUS staining was observed in vascular tissues. Treatment with $\mathrm{AgNO}_{3}$ strongly induced ANAC042pro:GUS expression in roots within $24 \mathrm{~h}$, particularly below the hypocotyl-root junction and in mature regions of lateral roots (Fig. 6C). Intense GUS staining was observed within the upper part of the hypocotyledonous stem
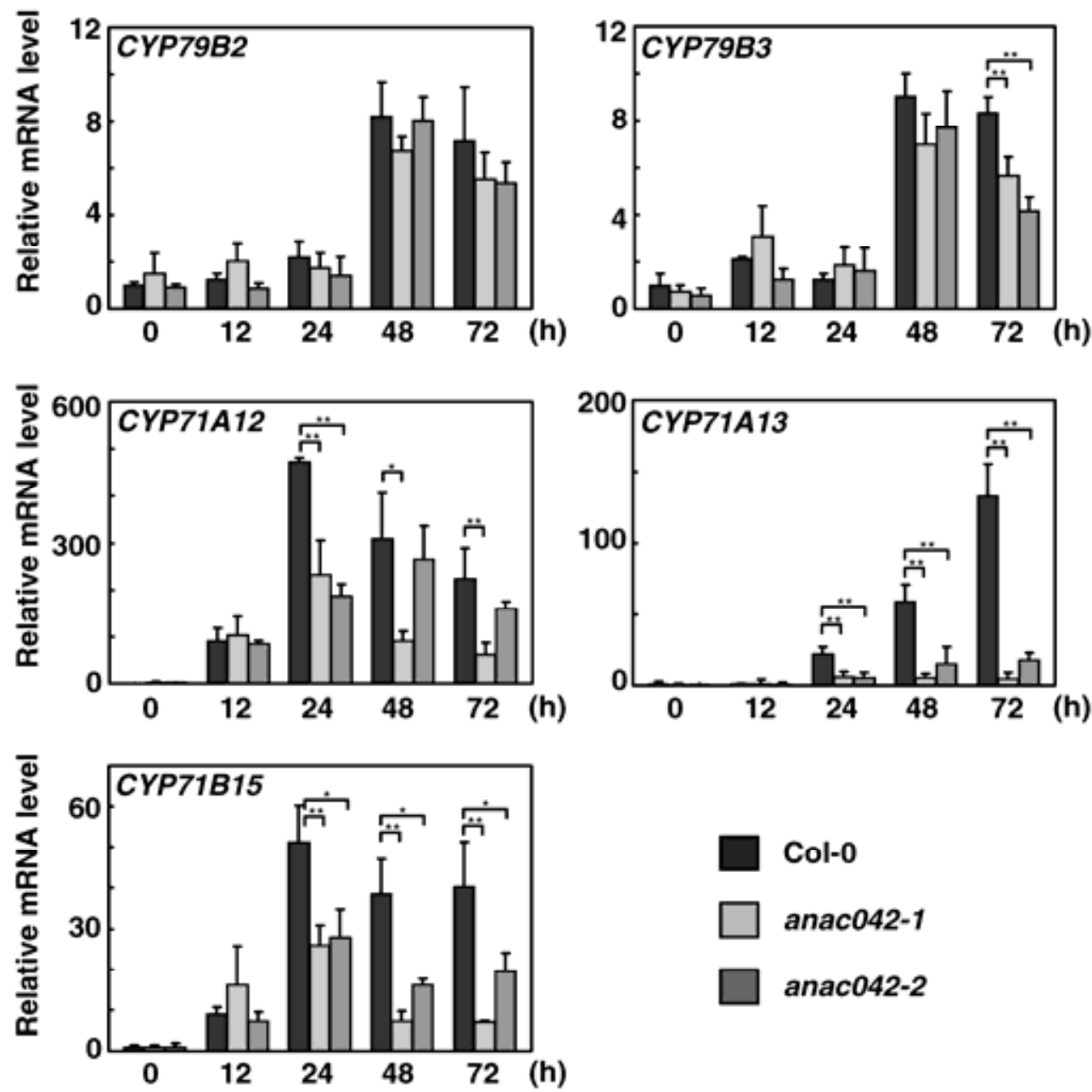

Fig. 5. Expression levels of the camalexin biosynthetic genes in anac042-1 and anac042-2 plant roots. Seed were germinated on GM agar plates, and 1-week-old seedlings were transferred to GM liquid culture medium. After 2 weeks, plants were treated with $0.1 \mathrm{mM} \mathrm{AgNO}_{3}$. Gene transcripts were quantified by realtime polymerase chain reaction (PCR) using gene-specific primers (Supplementary Table S3). Bar graphs show the changes in transcript levels relative to those in wild-type plants determined before $\mathrm{AgNO}_{3}$ treatment. Results represent one of three independent reproducible experiments; error bars are the standard deviation of biological triplicate; $*$ and $* *$ indicate $P$ value $<0.05$ and 0.01 , respectively, one-way analysis of variance with Dunnet's post-hoc test. 
and faintly developed in the cotyledons. No clear GUS staining was detected in other root tissues such as root tips and elongation zones. The small spots near the SAM also occurred during $\mathrm{AgNO}_{3}$ treatment. Within $48 \mathrm{~h}$ of $A$. brassicicola infection, ANAC042pro:GUS expression was induced at the infection sites in both rosette leaves and roots, indicating that ANACO42 expression was induced by the fungus without tissue or organ specificity (Fig. 6D and E).

Treatment with Flg22 induced ANAC042pro:GUS expression in a manner different from those observed with $\mathrm{AgNO}_{3}$ treatment and infection by A. brassicicola (Fig. 7A). Flg22 is an oligopeptide consisting of 22 conserved amino acids near the $\mathrm{N}$ terminus of flagellins, containing conserved MAMP epitopes (Felix et al. 1999). After $3 \mathrm{~h}$ of Flg22 treatment, GUS staining was observed in the root-elongation zone (Fig. 7A) but not in the shoots (data not shown), and it was abolished in the fls 2 mutant line (Fig. 7B). It was reported that CYP71A12, a camalexin
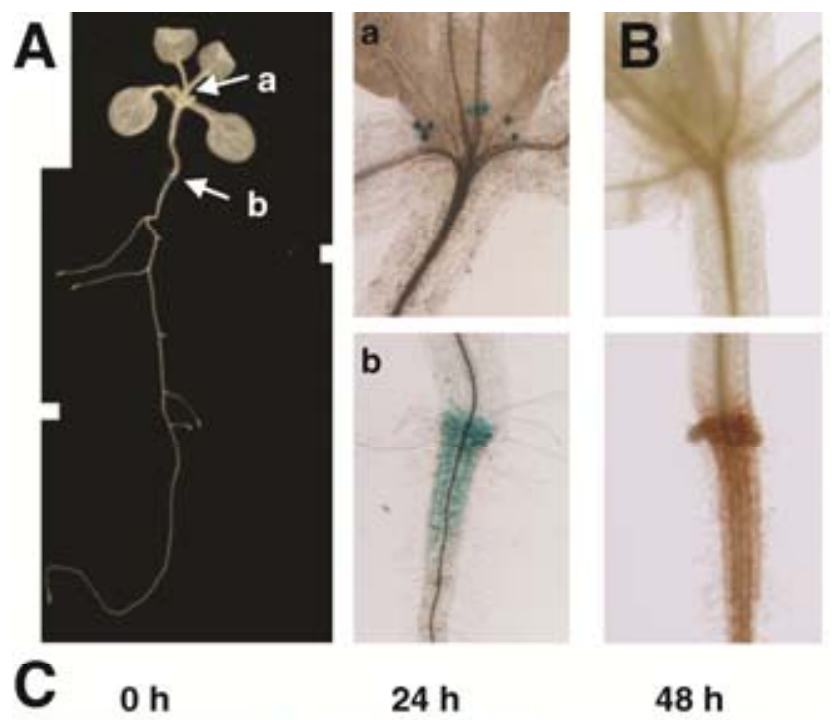

$24 \mathrm{~h}$
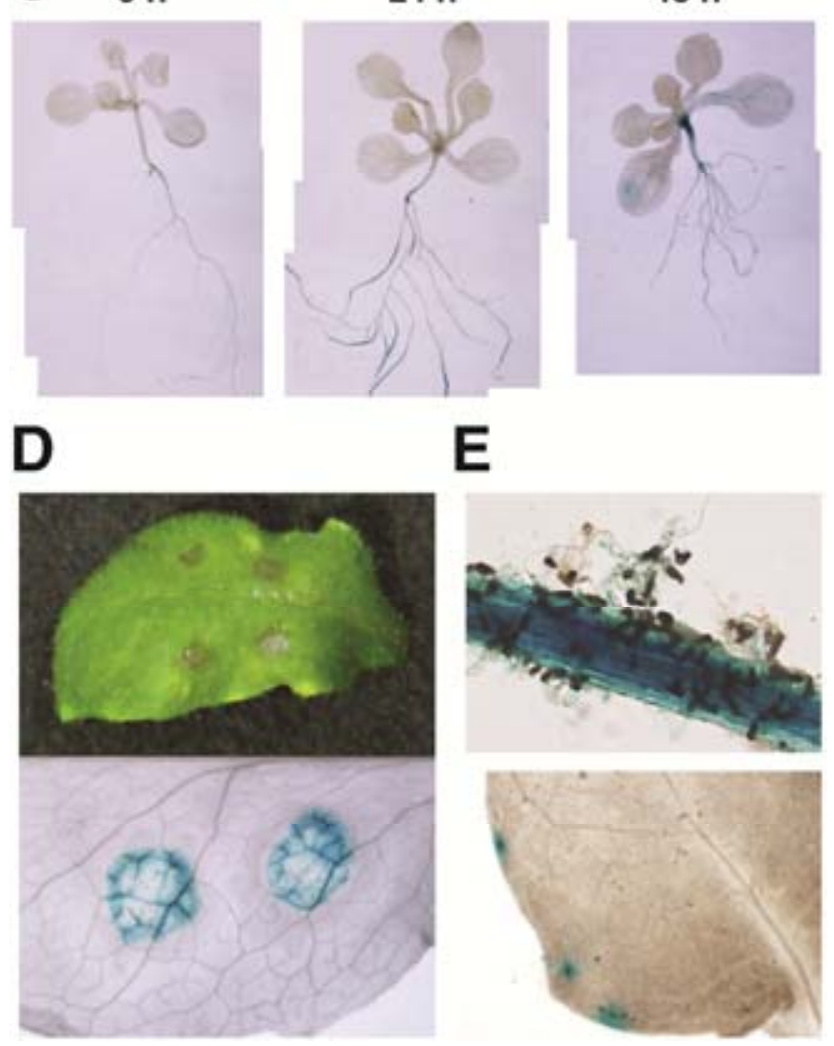

biosynthetic gene, was induced in the root-elongation zone by Flg22 (Millet et al. 2010), suggesting that ANAC042 may be involved in the regulation of Flg22-dependent induction of CYP71A12 in specific root tissues, where biosynthesis and exudation of camalexin were envisaged (Millet et al. 2010). The Flg22-dependent camalexin induction in the roots was greatly reduced in the anac042 mutant lines; the root camalexin exudation levels from anac042 mutants were only 6 to $10 \%$ of that from wild-type plants (Supplementary Fig. S4). It is noteworthy that Flg22-dependent ANAC042pro:GUS expression was restricted to specific root regions, contrasting with the induction by fungal infection, which was observed at the site of infection independent of tissues or organs (Fig. 6D and E).

Heat-treated extracts from DC3000 and avrRPT2 induced ANAC042pro:GUS expression in the root-elongation zone, the same site as detected for Flg22-dependent ANAC042pro:GUS expression, whereas GUS staining was not clearly detected in plants infected by live bacteria of DC3000 and avrRPT2 (Fig. 7C). These results indicated that $P$. syringae pv. tomato bacterial pathogens, regardless of strain compatibility or incompatibility, might have suppressed expression of ANACO42 in the root-elongation zone. In support of this observation, Flg22-dependent expression of the ANAC042pro:GUS reporter in the elongation zone was suppressed in the presence of $P$. syringae pv. tomato strains (Supplementary Fig. S5). Millet and associates (2010) reported that Arabidopsis roots exert tissue-specific MAMP responses against pathogen infection and that the MAMP-elicited signaling pathways are blocked by pathogenencoded mechanisms, including the activity of the phytotoxin coronatine, an Ile-jasmonic acid mimic produced by $P$. syringae pathovars. This might also be true for the suppression of the Flg22-dependent $A N A C 042$ induction. Further studies were performed focusing on ANAC042pro:GUS expression in the rootelongation zone.

\section{Signaling cascades for $A N A C 042$ induction.}

The Flg22-dependent ANAC042pro:GUS expression was specifically and strongly induced in the root-elongation zone as described above (Fig. 7A), and was suppressed in an $\mathrm{fls} 2$ mutant line (Fig. 7B). In addition, ANAC042pro:GUS induction was strongly inhibited in the presence of general kinase

Fig. 6. ANAC042pro: $\beta$-glucuronidase (GUS) reporter expression. A, Six independent ANAC042pro:GUS reporter lines were generated and used for the GUS-reporter assay. Results were reproducible among these GUS-reporter lines. One of the representative GUS-reporter lines was used for further experiments. One week after germination, GUS staining was detected as small spots a, near the shoot apical meristem region and $\mathbf{b}$, in the root-hypocotyl junction region. The whole seedling picture was prepared by assembling microscopic graphic images recorded from different parts of a selected seedling. B, Staining with 3,3' diaminobenzidine tetrahydrochloride indicated $\mathrm{H}_{2} \mathrm{O}_{2}$ generation at the root-hypocotyl junction. C, Induction of ANACO42pro: $G U S$ by $\mathrm{AgNO}_{3}$. Seedlings (10 days old) of the ANAC042pro:GUS reporter line were transferred to GM agar plates containing $0.1 \mathrm{mM} \mathrm{AgNO}_{3}$ and sprayed with $5 \mathrm{mM}$ $\mathrm{AgNO}_{3}$ in $0.02 \%$ Silwet L-77. Plants were sampled 24 and $48 \mathrm{~h}$ after treatment. Whole seedling pictures were prepared by assembling several microscopic images recorded from different parts of selected seedlings. D, Induction of ANAC042pro:GUS by infection with Alternaria brasscicola. Plants (30 day old) of the ANAC042pro:GUS line grown in soil were used for the fungal infection studies. Drops $(5 \mu \mathrm{l})$ of fungal spore suspension $\left(5 \times 10^{5}\right.$ spores $\left./ \mathrm{ml}\right)$ were applied onto rosette leaves. Leaves were subjected to the GUS-reporter assay $48 \mathrm{~h}$ after inoculation. E, Seedlings ( 1 week old) grown on GM agar plates were submerged in fungal spore suspension $\left(5 \times 10^{4}\right.$ spores $\left./ \mathrm{ml}\right)$, and plants were used for the GUS-reporter assay $12 \mathrm{~h}$ after inoculation. GUS-reporter induction was observed at the sites of fungal spore infection in both roots and leaves. 
inhibitor K252a and brefeldin A (BFA) (Fig. 8A). K252a inhibits activation of FLS2, as well as FLS2-BAK1 interaction (Chinchilla et al. 2007), and BFA inhibits FLS2 recycling in the intracellular membrane network (Robatzek et al. 2006). The Flg22-dependent ANAC042pro:GUS expression in the rootelongation zone was virtually unaffected in the salicylic acid (SA)-deficient mutant sid2-2 (Wildermuth et al. 2001), indicating that ANAC042 induction was independent of the SAsignaling pathway (Fig. 8B). Furthermore, ANAC042 expression was not significantly induced by SA in the roots (Supplementary Fig. S6). That is, an SA-independent mechanism might primarily function to induce $A N A C O 42$ in the root-elongation zone. On the other hand, ANAC042 expression was strongly induced by application of 1-aminocyclopropane-1-carboxylic acid (ACC), and Flg22-dependent induction was suppressed in the ein2-1 mutant plants (Fig. 8B) (Guzmán and Ecker 1990) and in the presence of 2-aminoethoxyvinyl-glycine (Fig. 8C), an ethylene $(\mathrm{Et})$ biosynthesis inhibitor, indicating that Flg22dependent ANAC042 induction in the root-elongation zone was regulated by the Et-signaling pathway. The GUS-reporter induction was also inhibited by methyl jasmonate (MeJA) (Fig. 8C), a finding consistent with inhibition by jasmonic acid (JA) of Flg22-dependent induction of CYP71A12 in the root-elongation zone (Millet et al. 2010). It is possible that Flg22-dependent induction of ANACO42 might be under the control of the same signaling pathway as that which regulates $C Y P 71 A 12 \mathrm{ex}-$ pression in the root-elongation zone.

\section{DISCUSSION}

ANAC042 and camalexin biosynthesis.

We demonstrated that ANACO42, an NAC transcription factor family gene, is involved in the induction of camalexin biosynthesis. The T-DNA insertion mutants defective for ANACO42 expression were highly susceptible to infection by $A$. brassicicola (Fig. 4D), and the mutant lines displayed reduced expres- sion levels of the camalexin biosynthetic genes $C Y P 71 A 12$, CYP71A13, and CYP71B15 (Fig. 5). ANAC042pro:GUS induction in response to $A$. brassicicola infection, in both leaves and roots, was observed at the site of the fungal infection (Fig. 6D and E). In contrast, Flg22-dependent ANAC042pro: GUS induction was restricted to the root-elongation zone (Fig. 7A), where CYP71A12 and MYB51 were specifically induced by elicitation with Flg22 (Millet et al. 2010). These results suggested that ANACO42 is involved in the regulation of metabolic activities evoked in specific tissues or organs in response to different pathogens. The transcript levels of camalexin biosynthetic genes CYP71A12, CYP71A13, and CYP71B15/PAD3 were notably reduced in the roots of anac042-1 and anac042-2 mutant lines treated with $\mathrm{AgNO}_{3}$ (Fig. 5). In contrast, the $C Y P 79 B 2$ and $C Y P 79 B 3$ transcript accumulation levels were not strongly affected (Fig. 5). These results suggested that ANAC042 might be involved in the induction of camalexin biosynthesis through transcriptional regulation of these $\mathrm{P} 450$ genes involved in the biosynthetic steps downstream of IAOx production. It remains to be clarified whether or not ANACO42 directly regulates expression of these $\mathrm{P} 450$ genes.

\section{Regulation of $A N A C 042$.}

Camalexin biosynthesis is induced in response to pathogen infection through complex signaling networks, including SA-, JA-, and Et-dependent pathways, as well as glutathione status and ROS generation (Glawischnig 2006; Glazebrook 2005). The GUS-reporter assays suggested that camalexin biosynthesis was induced in specialized tissues or organs in response to differential signals (Figs. 6 and 7). The Flg22-dependent expression of ANAC042pro:GUS was specifically and strongly induced in the root-elongation zone (Fig. 7A), and the induction was blocked in the presence of K252a and BFA (Fig. 8A), which both inhibit the FLS2-dependent signaling pathway (Chinchilla et al. 2007; Robatzek et al. 2006). Millet and associates (2010) reported that Flg22 elicits a strong response in

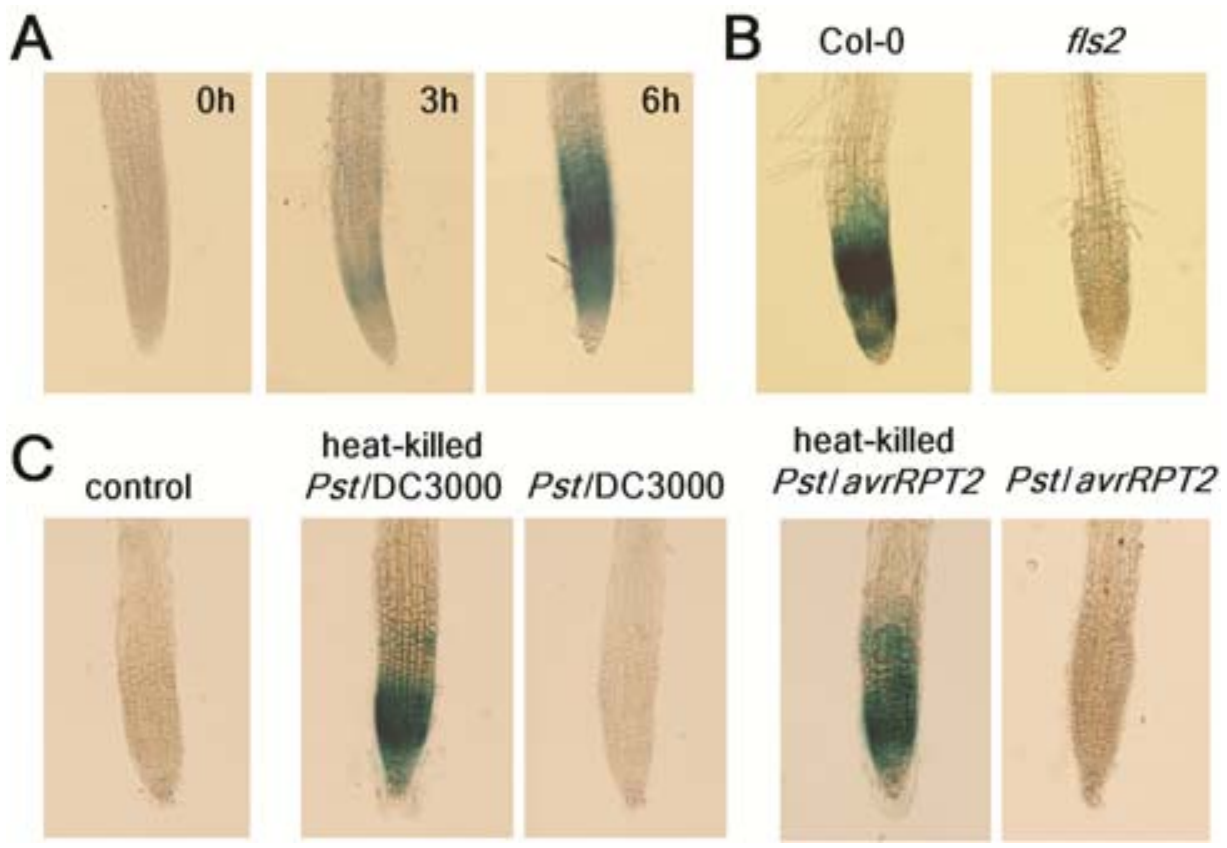

Fig. 7. Induction of ANAC042pro: $\beta$-glucuronidase (GUS) by application of heat-killed P. syringae extracts and Flg22. A, Seedlings (1 week old) of the ANAC042pro:GUS reporter line were cultured in liquid medium for 2 days. Flg22 (100 nM) was added to the culture medium, and the seedlings were sampled for the GUS-staining assay 3 and $6 \mathrm{~h}$ after Flg22 treatment. B, The fls 2 mutant plants expressing ANAC042pro:GUS were generated by crossing with the GUS-reporter line and used for the GUS-staining assay. Seedlings (1 week old) were treated with $100 \mathrm{nM}$ Flg22. C, Seedlings (1 week old) of the ANAC042pro:GUS reporter line were cultured in liquid medium for 2 days. Either a live or heat-killed bacterial suspension was added to the medium to give an optical density at $600 \mathrm{~nm}=0.1$ and incubated for $5 \mathrm{~h}$, after which the plants were subjected to the GUS-staining assay. A mock treatment with $\mathrm{H}_{2} \mathrm{O}$ (control) was carried out in parallel. 
Arabidopsis roots leading to the induction of CYP71A12-dependent exudation of camalexin and callose deposition, a histochemical marker for positive disease resistance responses. Millet and associates (2010) also demonstrated that Et signaling and biosynthesis of 4-methoxy-indole-3-ylmethylglucosinolate as well as its possible degradation products, but not SA or JA signaling, play major roles in Flg22-dependent induction of CYP71A12 expression and callose deposition. As reported for Flg22-induced expression of CYP71A12 (Millet et al. 2010), the ANAC042pro:GUS reporter expression was also blocked in the presence of MeJA (Fig. 8), supporting the possibility that ANACO42 and CYP71A12 are regulated by the same signaling pathway responding to Flg22. On the other hand, callose deposition was not blocked in the roots of anac042 mutant lines (Supplementary Fig. S7).

ANAC042 expression was strongly induced in the roots by application of ACC, and ANAC042pro:GUS reporter expression in the root-elongation zone was repressed under the ein2-1 background (Fig. 8B). EIN2 is a membrane metal transporterlike protein that plays a crucial role in Et signaling (Alonso et al. 1999). These results indicated that Flg22-dependent ANAC042 induction was activated through an Et-signaling pathway. Et signaling is involved in the FLS2 expression and
Flg22-induced ROS production (Mersmann et al. 2010), and ROS production is essential for induction of camalexin biosynthesis (Denby et al. 2005; Glawishing 2006; Tierens et al. 2002). That is, Flg22-dependent ANAC042 expression might also be regulated downstream of ROS production and through the Et-signaling pathway. Staining with DAB suggested that ROS generation occurred in the same tissues as ANAC042pro: GUS reporter expression (Fig. 6A and B), supporting the notion that $A N A C 042$ expression might be a downstream event of ROS generation.

Boudsocq and associates (2010) demonstrated Flg22-dependent activation of calcium-dependent protein kinases (CDPK) as $\mathrm{Ca}^{2+}$ sensors playing crucial roles in disease resistance in Arabidopsis, with potential target genes of CYP81F2, PEN2, and MYB51 as well as ANACO42, MYB122, CYP71A12, and $C Y P 71 A 13$, and suggested the possible involvement of CDPK in regulating ROS production through phosphorylation of NADPH oxidase RbohB. Production of ROS by RbohD is also an early event in Flg22-triggered responses (Zhang et al. 2007). Boudsocq and associates (2010) reported that activation of CDPK by Flg22 was abolished in the fls 2 mutant and by $\mathrm{Ca}^{2+}$ blockers ( $\mathrm{La}^{3+}$ and BAPTA). In this study, Flg22-dependent ANAC042pro:GUS expression, which was suppressed in
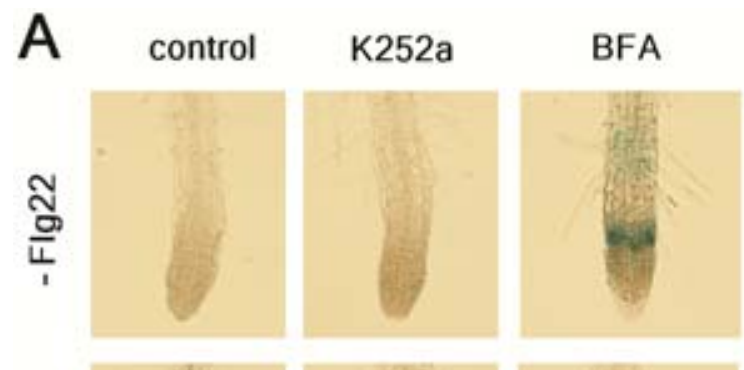

BAPTA
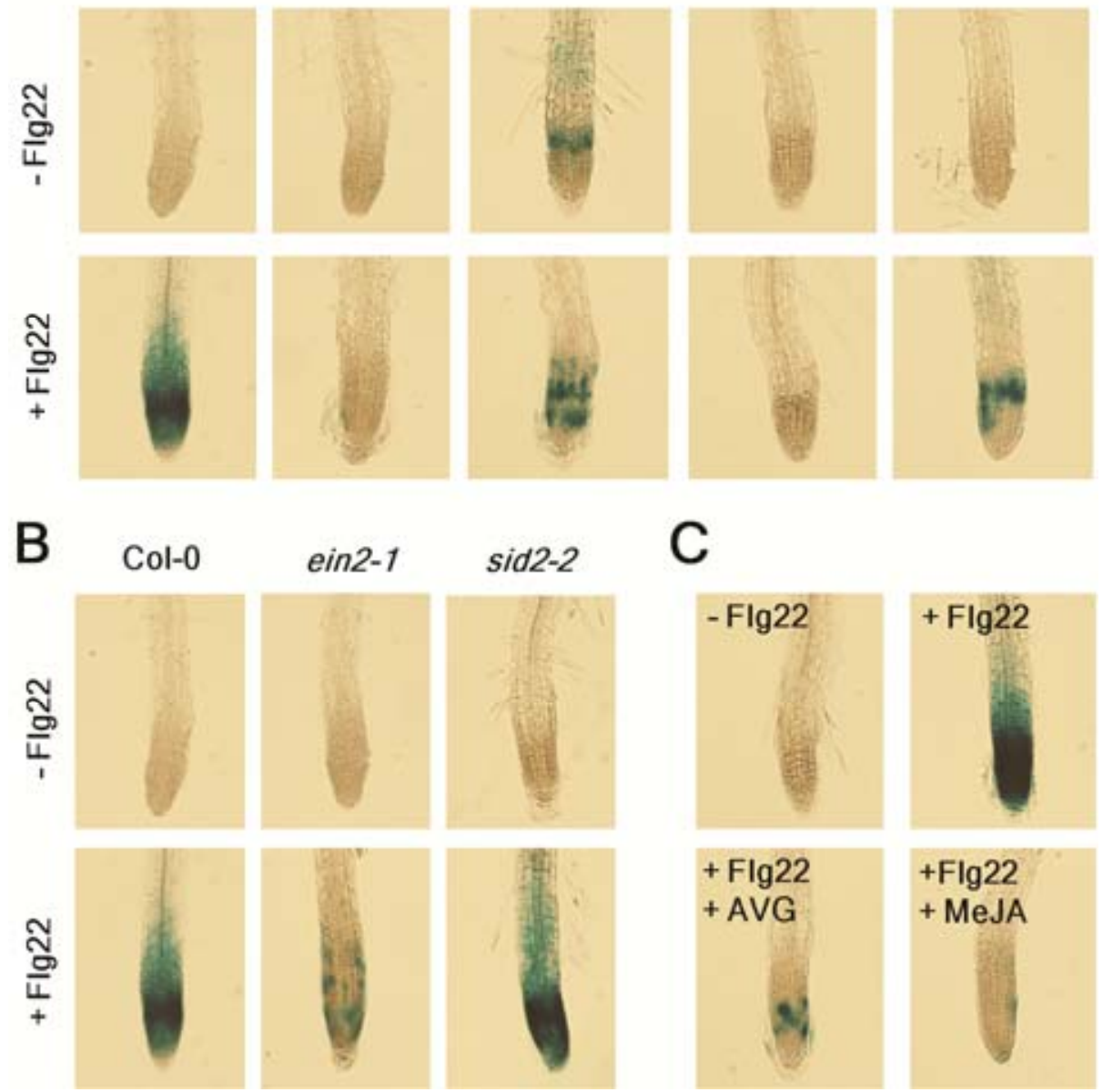

C
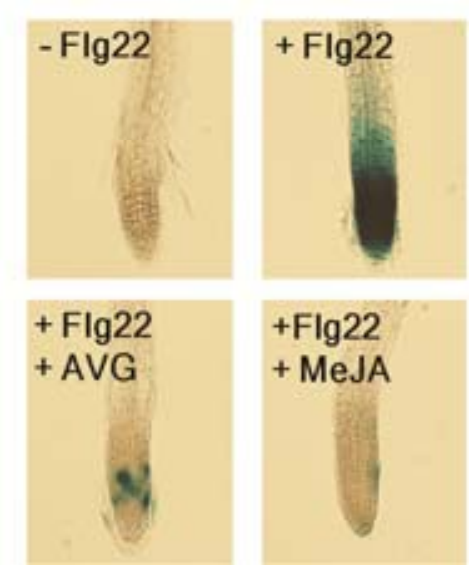

Fig. 8. Inhibition of ANAC042pro: $\beta$-glucuronidase (GUS) induction. Seedlings (1 week old) of the ANAC042pro:GUS reporter line were cultured in liquid medium for 2 days. A, Seedlings were cultured in the presence of either K252a ( $1 \mu \mathrm{M})$ or brefeldin A (100 $\mu \mathrm{g} / \mathrm{ml}) \mathrm{for} 6 \mathrm{~h}$. Flg22 (100 $\mathrm{nM}) \mathrm{was}$ added to the culture medium, and the seedlings were sampled for the GUS-staining assay $5 \mathrm{~h}$ after Flg22 addition. Seedlings were co-cultured for $6 \mathrm{~h}$ with BAPTA (final $10 \mathrm{mM}$ ) or EGTA (final $5 \mathrm{mM}$ ) and treated with $100 \mathrm{nM}$ Flg22 for $5 \mathrm{~h}$. A mock treatment without inhibitors (control) was carried out in parallel. B, The ein21 and sid2-2 plants carrying ANAC042pro:GUS were used for the GUS-staining assay. Seedlings (1 week old) were treated for $5 \mathrm{~h}$ with $100 \mathrm{nM}$ Flg22. C, Seedlings (1 week old) of the ANAC042pro:GUS reporter line were cultured in liquid medium for 2 days. After co-incubation for $6 \mathrm{~h}$ with $10 \mu \mathrm{M} 2$-aminoethoxyvinyl-glycine (AVG), the seedlings were treated with $100 \mathrm{nM}$ Flg22. Seedlings ( 1 week old) were treated for $5 \mathrm{~h}$ with $100 \mathrm{nM}$ Flg22 in the presence of $10 \mu \mathrm{M}$ methyl-jasmonate (MeJA). 
the fls 2 mutant plants (Fig. 7B), was blocked in the presence of BAPTA or EGTA (Fig. 8A). It is possible that Flg22-dependent ANACO42 induction is one of the downstream events of the signal transduction pathways mediated by CDPK, inducing the camalexin biosynthetic P450 genes $C Y P 71 A 12$ and $C Y P 71 A 13$, and $C Y P 71 B 15 / P A D 3$. The strong induction of $A N A C 042$ by acifluorfen treatment could be ascribed to the involvement of a ROS-dependent signaling pathway.

\section{Signaling network.}

We have demonstrated that ANACO42 could be involved in the transcriptional regulation of $C Y P 71 A 12, C Y P 71 A 13$, and $C Y P 71 B 15$, leading to the induction of camalexin biosynthesis. It has been reported that the camalexin biosynthetic genes $C Y P 71 A 13$ and $C Y P 71 B 15 / P A D 3$ are regulated by the transcription factor WRKY33 (Petersen et al. 2008). MPK4 and its substrate MKS1 interact with WRKY33 in vivo, and WRKY33 is released from complexes with MPK4 upon infection (Qui et al. 2008). Mao and associates (2011) demonstrated, using Arabidopsis seedlings, that WRKY33 is phosphorylated by MPK3/MPK6 inducing camalexin biosynthesis in response to infection by $B$. cinerea. Furthermore, their results showed that MPK4 is not required for induction of camalexin biosynthesis by fungal infection. That is, MPK4 and MPK3/MPK6 could play different roles in camalexin induction in response to different pathogens; MPK3/MPK6 activity is critical for WRKY33 phosphorylation required for camalexin induction by a fungal pathogen (Mao et al. 2011), while MPK4 is involved in camalexin induction by a bacterial pathogen (Qiu et al. 2008). Suarez-Rodriguez and associates (2007) reported that MEKK1 is required for Flg22induced activation of MPK4 but not MPK3 or MPK6. Zheng and associates (2006) suggested that WRKY33 regulates the antagonistic relationship between defense pathways mediating responses to $P$. syringae and necrotrophic fungal pathogens. Our results indicated that ANAC042 induction by Flg22 was dependent on Et signaling, whereas camalexin induction following MPK3/MPK6 activation is independent of Et signaling (Ren et al. 2008). Transcript levels of WRKY33 were not different between the roots of wild-type and anac042 mutants in the $\mathrm{AgNO}_{3}$ treatment (Supplementary Fig. S8). These results suggested that ANAC042 might function independently from the WRKY33-dependent signaling pathways. Possible crosstalk of ANAC042- and WRKY33-dependent pathways in the induction of camalexin biosynthesis remains to be clarified.

In this study, we identified ANACO42 as a key transcription factor family gene in the regulation of camalexin biosynthesis in Arabidopsis and presented evidence for a previously unknown signaling pathway involved in the phytoalexin biosynthesis induction. Further characterization of ANACO42 functions among disease resistance responses should add a new dimension to understand the complex signaling networks for activation and coordination of metabolic activities in response to biotic and abiotic stresses.

\section{MATERIALS AND METHODS}

\section{Plant materials and growth conditions.}

Arabidopsis thaliana ecotype Columbia (Col-0) (Lehle Seeds, Round Rock, TX, U.S.A.) seedlings were grown at $22^{\circ} \mathrm{C}$ under either continuous light or a photoperiod of 16 and $8 \mathrm{~h}$ (light and darkness, respectively) $\left(100 \mu \mathrm{E} / \mathrm{m}^{2} / \mathrm{s}\right)$. Arabidopsis seedlings were germinated under sterile conditions on $0.8 \%$ (wt/vol) agar plates containing a germination medium (GM) supplemented with 1× Murashige and Skoog salts and 1\% (wt/vol) sucrose (Morikawa et al. 2006). The seedlings were then transferred to GM liquid culture and shaken at $100 \mathrm{rpm}$ and $22^{\circ} \mathrm{C}$ under continuous light.

\section{Plant treatments.}

For induction of camalexin biosynthesis, liquid-cultured plants were treated with $0.1 \mathrm{mM} \mathrm{AgNO}_{3}$. Four-week-old plants in soil were sprayed with $5 \mathrm{mM} \mathrm{AgNO}_{3}$ dissolved in $0.02 \%$ Silwet L-77 (Nihon Yunika, Tokyo). Acifluorfen (0.1 mM in $0.02 \%$ Silwet L-77) was sprayed over the plants. A stock solution of Flg22 (Hokkaido System Science, Hokkaido, Japan) was prepared at $1 \mathrm{mM}$ in $\mathrm{H}_{2} \mathrm{O}$ and diluted to $100 \mathrm{nM}$ for GUSreporter assays (Millet et al. 2010). Plants were treated with SA (Wako Pure Chemicals, Osaka, Japan), MeJA (Wako Pure Chemicals), and 1-aminocyclopropane-1-carboxylic-acid (Wako Pure Chemicals) at the concentrations of 0.1 and $1 \mu \mathrm{M}$. At least three independent replications were performed for each experiment. For determination of camalexin exudation, roots were cut from six plants and placed in wells containing $1 \mathrm{ml}$ of liquid GM supplemented with $1 \mu \mathrm{M}$ Flg22 in 12-well microtiter dishes. Culture medium samples were collected and stored at $-80^{\circ} \mathrm{C}$ until use.

\section{Pathogen infection.}

For pathogen treatments, mutants and wild-type Col plants were grown on soil under a photoperiod of 16 and $8 \mathrm{~h}$ (light and darkness, respectively) in a growth chamber. Alternaria brassicicola (strain NBRC 31226; National Institute of Technology and Evaluation, Tokyo) was maintained on potato-dextrose agar medium and incubated at $25^{\circ} \mathrm{C}$. Spores were suspended in distilled water for plant inoculation. A single drop of $10 \mu \mathrm{l}$ of spore suspension $\left(5 \times 10^{5}\right.$ spores $\left./ \mathrm{ml}\right)$ was applied to each detached leaf at the beginning of the light period. Bacterial strains of $P$. syringae pv. tomato DC3000 harboring a plasmid with or without the avirulence gene avrRPT2 were used for infection assays. $P$. syringae pv. tomato strains were cultured on King's B agar plates or King's B liquid medium supplemented with rifampicin (50 $\mu \mathrm{g} / \mathrm{ml}$ ) for selection (Lawton et al. 1996). For infection, bacteria were grown overnight in King's B medium supplemented with an appropriate antibiotic at $28^{\circ} \mathrm{C}$ (Lawton et al. 1996). Cells were collected by centrifugation, washed three times with water, resuspended in $10 \mathrm{mM} \mathrm{MgCl}_{2}$ at an optical density at $600 \mathrm{~nm}$ $\left(\mathrm{OD}_{600}\right)=0.10$, and then diluted to $1 \times 10^{7} \mathrm{CFU} / \mathrm{ml}$ in $10 \mathrm{mM}$ $\mathrm{MgCl}_{2}$. For infection in the liquid culture medium, the bacterial suspension was added to give a final $\mathrm{OD}_{600}$ of 0.1 . The heattreated bacterial extracts were obtained by boiling the bacterial suspension for $10 \mathrm{~min}$ in $1.5-\mathrm{ml}$ microcentrifuge tubes.

\section{Mutant plants.}

The T-DNA insertion events anac042-1 (SALK_036473) and anac042-2 (SM_3_17839) were selected from a database search using the SIGnAL Arabidopsis Gene Mapping Tool (Alonso et al. 2003). The seed were obtained from the Arabidopsis Biological Resource Center (ABRC). A gene-specific primer set (ANAC042-LP and ANAC042-RP) and T-DNA border primers (LBa1, Spm32, and LB1) were used to clarify the T-DNA insertion events (Supplementary Table S3). Individual plants homozygous for T-DNA insertion events were identified by PCR screening. Seed of ein2-1 (Guzmán and Ecker 1990), cyp71a13-1 (SALK_105136) (Nafisi et al. 2007), and fls2 SAIL (SAIL_691_C04) (Melotto et al. 2006) were obtained from the ABRC stock list. Seed of the sid2-2 line (Wildermuth et al. 2001) were supplied by K. Shirasu of RIKEN Japan.

\section{Gene expression analyses.}

Total RNA was extracted using the RNeasy Plant Mini Kit (Qiagen, Tokyo) and treated with RNase-free DNase (Qiagen). First-strand cDNA was synthesized using a Takara RNA poly- 
merase chain reaction (PCR) kit (AMV) version 3.0 (Takara, Kyoto, Japan) in a 10- $\mu$ l reaction mixture containing $500 \mathrm{ng}$ of total RNA using an oligo $(\mathrm{dT})_{16}$ as the reverse primer. The reverse-transcription reactions were carried out at $30^{\circ} \mathrm{C}$ for 10 min, $50^{\circ} \mathrm{C}$ for $30 \mathrm{~min}$, and $95^{\circ} \mathrm{C}$ for $5 \mathrm{~min}$, then chilled to $5^{\circ} \mathrm{C}$ for $5 \mathrm{~min}$. The PCR was performed using $0.5 \mu \mathrm{l}$ of the reversetranscription products as template in a $10-\mu 1$ reaction mixture containing $1 \mathrm{mM} \mathrm{MgCl}, 0.2 \mathrm{mM}$ dNTP mixture, Takara Ex Taq HS (Takara) at $0.025 \mathrm{U} / \mu \mathrm{l}$, and $0.2 \mu \mathrm{M}$ primers using the Takara RNA PCR Kit (AMV) version 3.0 (Takara). Semiquantitative PCR (reaction cycles specified in the figures) was carried out at $94^{\circ} \mathrm{C}$ for $30 \mathrm{~s}, 58^{\circ} \mathrm{C}$ for $30 \mathrm{~s}$, and $72^{\circ} \mathrm{C}$ for $1 \mathrm{~min}$ followed by an extension period of $10 \mathrm{~min}$ at $72^{\circ} \mathrm{C}$. Amplification of each gene transcript was carried out using the gene-specific primer pairs, and aliquots of reaction products were taken to monitor the linear amplification conditions. The Arabidopsis ACTIN2 gene was used as an internal control using the primer pair Act2-F and Act2-R. Reaction products were separated in $1.5 \%$ (wt/vol) agarose gel by electrophoresis and visualized by SYBR green staining (SYBR GREEN I, Takara). Real-time PCR was carried out to determine gene transcript accumulation levels using a BioFlux LineGene (Toyobo, Osaka, Japan) and THUNDERBIRD SYBR qPCR Mix (Toyobo). Each primer set was evaluated in terms of amplification dynamic range as well as $R^{2}$ values, and amplification specificity was assessed by both melting curve analyses and agarose gel electrophoresis.

\section{Transcriptome analyses.}

Seedlings on GM agar plates (1 week after germination) were transferred to GM liquid culture and maintained for 2 weeks under continuous light. Plants were then treated with $0.1 \mathrm{mM} \mathrm{AgNO}{ }_{3}$ and sampled at 48 and $72 \mathrm{~h}$ after the treatment. Total RNA (in three independent biological replicates) was prepared using the RNeasy Plant Mini Kit (Qiagen). An Arabidopsis 3 oligo microarray kit $(4 \times 44 \mathrm{~K}$; Agilent Technologies, Tokyo) and a Quick Amp Labeling Kit (version 5.7; Agilent Technologies) were used for the analysis according to the manufacturer's instructions. Cy3-labeled cRNA was prepared using the Quick Amp Labeling Kit, one color (Agilent Technologies). Feature Extraction and Image Analysis software (version 9.5.3.1; Agilent Technologies) was used to locate and delineate each spot in the array, and integration of the intensity, filtering, and normalization of each spot were performed using Gene Spring GX (version 8.0.0.0; Agilent Technologies).

\section{Gene co-expression analysis.}

Arabidopsis microarray datasets (3,654 assays of ATH1 format; Affymetrix) were obtained from the National Center for Biotechnology Information Gene Express Omnibus in September 2008, similar to the datasets utilized in the CoP database (Ogata et al. 2010). A dataset of gene-to-gene correlation coefficients was calculated on the basis of gene expression profiles in the datasets. By applying the Confeito algorithm (Ogata et al. 2009), which is a network module analytic method to assemble local modules with tight interconnections, to the correlation dataset, we acquired local modules including genes encoding ANAC042 (At2g43000), MYB51 (At1g18570), and WRKY70 (At3g56400) as target genes.

\section{ANAC042-GFP fusion protein.}

The entire coding region of ANAC042 cDNA was amplified using the primer set ANAC042-FwXba1 and ANAC042RvGFPfusion, and the enhanced green fluorescence protein (EGFP) coding sequence was amplified using the primer set GFP-FwANAC042fusion and GFP-RvSacI-BamHI. These PCR products were used for second-round PCR amplification using the ANAC042-FwXbaI and GFP-RvSacI-BamHI primers to amplify a cDNA (ANAC042-GFP) for an ANAC042 protein with C-terminally fused EGFP protein. The ANAC042-GFP

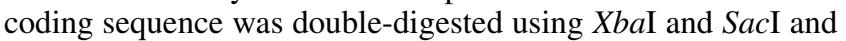
inserted into a pBin-based binary expression vector (Morikawa et al. 2006) to obtain a plasmid, p35S-ANAC042:EGFP, for transformation using the floral dip method.

\section{ANAC042pro:GUS reporter.}

For promoter: GUS reporter analyses, the 5'-promoter region of ANAC042 (1.5 kbp in length) was amplified by PCR from genomic DNA using the primer set ANAC042pro1500FwHindIII and ANAC042pro1500-RvGUSfusion. A GUS reporter coding sequence was amplified using the pBI101 plasmid (Clontech, Palo Alto, CA, U.S.A.) as the template using the primer set GUS-FwANAC042profusion and GUS-Rv. These PCR products were mixed and used for the secondround PCR using the primers ANAC042pro1500-FwHindIII and GUS-Rv to obtain a transcriptional fusion of the ANACO42 promoter: GUS reporter. The PCR product was cloned into the pDrive vector (Qiagen) and double digested with HindIII and MunI. The restriction fragments were excised and subcloned into the plant transformation vector pBI101 (Clontech) to give pBI101-ANAC042pro:GUS.

\section{Plant transformation.}

Plant expression plasmids were electroporated into Agrobacterium tumefaciens EHA105 and transformed into Arabidopsis using the floral dip method (Clough and Bent 1998). $\mathrm{T}_{1}$ seed were screened on GM agar plates containing kanamycin at $25 \mu \mathrm{g} / \mathrm{ml}$, and resistant seedlings were transferred to soil and allowed to set seed. Homozygous lines were selected by examining the kanamycin resistance of $\mathrm{T}_{3}$ seedlings. Lines homozygous for ANAC042pro:GUS reporter expression were crossed with either ein2-1 (Guzmán and Ecker 1990) or sid2-2 lines (Wildermuth et al. 2001). Homozygous ein2-1 progeny were screened by the Et sensitivity of hypocotyls, and sid2-2 homozygous lines were identified by PCR using genomic DNA as the template and either the primer set sid2-LP1 and sid2-RP, or sid2-LP2 and sid2-RP. F3 populations were used for the GUS-reporter assays.

\section{Camalexin analysis.}

Plant tissues were frozen and ground to powder in liquid $\mathrm{N}_{2}$. The frozen powders were extracted in $80 \%$ methanol containing 6-fluoroindole-3-carboxaldehyde (Sigma-Aldrich, St. Louis) at $1 \mathrm{mg} / \mathrm{ml}$ as an internal standard according to the method described by Loeffler and associates (2005). The homogenates were centrifuged at $10,000 \times g$ for $10 \mathrm{~min}$, and the supernatants were filtered through disposable membrane filter units (DISMIC-13JP; Advantec, Tokyo), evaporated under $\mathrm{N}_{2}$ atmosphere, and stored at $-80^{\circ} \mathrm{C}$ until use. Camalexin was determined by high-performance liquid chromatography (305/306 Pumps; Gilson Inc., Middleton, WI, U.S.A.) with a reverse-phase column (COSMOSIL 5C18-AR-II, $4.6 \times 150 \mathrm{~mm}$; Nacalai Tesque, Inc., Kyoto, Japan) at a column oven temperature of $40^{\circ} \mathrm{C}$. The elution was performed in a linear gradient with a flow rate of 1 $\mathrm{ml} / \mathrm{min}$ using $\mathrm{H}_{2} \mathrm{O}$ as solvent $\mathrm{A}$ and methanol as solvent $\mathrm{B}(0$ to $7 \mathrm{~min}$, linear gradient from 60 to $90 \% \mathrm{~B}$; 7 to $12 \mathrm{~min}$, isocratic $100 \% \mathrm{~B} ; 12$ to $15 \mathrm{~min}$, isocratic $60 \% \mathrm{~B}$ ). Camalexin was detected using a fluorometer with excitation at $318 \mathrm{~nm}$ and emission at $370 \mathrm{~nm}$ (Gilson 122; Gilson) and quantified from the camalexin peak area using Unipoint (version 5.11; Gilson). Camalexin was identified from ultra-high-resolution mass spectral data acquired using an IonSpec Explorer FT-ICR/MS (Fourier-transform ion cyclotron resonance mass spectrometry) 
(IonSpec Inc., Lake Forest, CA, U.S.A.) with a 7-tesla magnet (Supplementary Fig. S9). For the determination of root camalexin exudation, the stored culture medium samples were applied to solid-phase extraction tubes (Supleco DiscoveryDSC18; Sigma-Aldrich) following the manufacturer's instructions. The tubes were washed with $1 \mathrm{ml}$ of $5 \%$ acetonitrile, and bound compounds were eluted with $2 \mathrm{ml}$ of $100 \%$ acetonitrile. The eluates were evaporated to dryness in vacuo and redissolved in $20 \mu \mathrm{l}$ of $100 \%$ methanol for liquid chromatography MS analysis by electrospray ionization in positive mode (Nano Frontier LD; Hitachi High-Technologies Corp., Tokyo).

\section{Plant analyses.}

$\mathrm{T}_{2}$ plants expressing the ANAC042:EGFP protein were germinated on GM agar plates, and the GFP localization was analyzed by confocal microscopic analysis using a Digital Eclipse C1si-Ready with TE2000-E microscopic system (Nikon, Tokyo). The ANAC042pro:GUS transgenic plants were first treated with $90 \%$ (vol/vol) ice-cold acetone for $1 \mathrm{~h}$ and submerged in GUS staining buffer containing $50 \mathrm{mM}$ sodium phosphate ( $\mathrm{pH} 7.0$ ), $10 \mathrm{mM}$ EDTA, $0.5 \mathrm{mM}$ potassium ferrocyanide, $0.5 \mathrm{mM}$ potassium ferricyanide, $0.1 \%$ (wt/vol) Triton $\mathrm{X}$ 100 , and 5-bromo-4-chloro-3-indolyl- $\beta$-D-glucuronide (Nacalai Tesque Inc.) at $0.5 \mathrm{mg} / \mathrm{ml}$. The tissues were then infiltrated with staining buffer under vacuum and incubated at $37^{\circ} \mathrm{C}$ (Jefferson 1987). After rinsing with water, tissues were cleared with ethanol/acetic acid (9:1, vol/vol), which was followed with washes using 90, 70, and 50\% (vol/vol) diluted ethanol. The tissues were then placed in $50 \%$ glycerol for subsequent photography. Generation of $\mathrm{H}_{2} \mathrm{O}_{2}$ was detected by endogenous peroxidase-dependent in situ histochemical staining using DAB (Thordal-Christensen et al. 1997). Tissues were prepared on a slide in $50 \%$ glycerol and examined using a light microscope with an image analyzer DP72 (IX81 and SZX61; Olympus, Tokyo).

\section{ACKNOWLEDGMENTS}

This work was supported by New Energy and Industrial Technology Development (as part of the project called Development of Fundamental Technologies for Controlling the Process of Material Production of Plants) and, in part, by the Ministry of Education, Culture, Sports, Science, and Technology of Japan (grant number 21580418). H. Saga., K. Kai., and T. Ogawa performed research; K. Kai., N. Sakurai, and D. Shibata contributed a new analytical tool; H. Suzuki and Y. Ogata analyzed data; and D. Ohta designed research and wrote the article. We thank K. Shirasu for providing sid2-2 seed.

\section{LITERATURE CITED}

Alonso, J. M., Hirayama, T., Roman, G., Nourizadeh, S., and Ecker, J. R. 1999. EIN2, a bifunctional transducer of ethylene and stress responses in Arabidopsis. Science 284:2148-2152.

Alonso, J. M., Stepanova, A. N., Leisse, T. J., Kim, C. J., Chen, H., Shinn, P., Stevenson, D. K., Zimmerman, J., Barajas, P., Cheuk, R., Gadrinab, C., Heller, C., Jeske, A., Koesema, E., Meyers, C. C., Parker, H., Prednis, L., Ansari, Y., Choy, N., Deen, H., Geralt, M., Hazari, N., Hom, E., Karnes, M., Mulholland, C., Ndubaku, R., Schmidt, I., Guzman, P., Aguilar-Henonin, L., Schmid, M., Weigel, D., Carter, D. E., Marchand, T., Risseeuw, E., Brogden, D., Zeko, A., Crosby, W. L., Berry, C. C., and Ecker, J. R. 2003. Genome-wide insertional mutagenesis of Arabidopsis thaliana. Science 301:653-657.

Ausubel, F. M., Katagiri, F., Mindrinos, M., and Glazebrook, J. 1995. Use of Arabidopsis thaliana defense-related mutants to dissect the plantresponse to pathogens. Proc. Natl. Acad. Sci. U.S.A. 92:4189-4196.

Böttcher, C., Westphal, L., Schmotz, C., Prade, E., Scheel, D., and Glawischnig, E. 2009. The Multifunctional enzyme CYP71B15 (PHYTOALEXIN DEFICIENT3) converts cysteine-indole-3-acetonitrile to camalexin in the indole-3-acetonitrile metabolic network of Arabidopsis thaliana. Plant Cell 21:1830-1845.

Boudsocq, M., Willmann, M.R., McCormack, M., Lee, H., Shan, L. B.,
He, P., Bush, J., Cheng, S. H., and Sheen, J. 2010. Differential innate immune signaling via $\mathrm{Ca}^{2+}$ sensor protein kinases. Nature 464:418-422.

Celenza, J. L., Quiel, J. A., Smolen, G. A., Merrikh, H., Silvestro, A. R., Normanly, J., and Bender, J. 2005. The Arabidopsis ATR1 Myb transcription factor controls indolic glucosinolate homeostasis. Plant Physiol. 137:253-262.

Chinchilla, D., Zipfel, C., Robatzek, S., Kemmerling, B., Nürnberger, T., Jones, J. D. G., Felix, G., and Boller, T. 2007. A flagellin-induced complex of the receptor FLS2 and BAK1 initiates plant defense. Nature 448:497-500.

Clough, S. J., and Bent, A. F. 1998. Floral dip: a simplified method for Agrobacterium-mediated transformation of Arabidopsis thaliana. Plant J. 16:735-743.

Denby, K. J., Jason, L. J. M., Murray, S. L., and Last, R. L. 2005. ups1, an Arabidopsis thaliana camalexin accumulation mutant defective in multiple defense signaling pathways. Plant J. 41:673-684.

Felix, G., Duran, J. D., Volko, S., Boller, T. 1999. Plants have a sensitive perception system for the most conserved domain of bacterial flagellin. Plant J. 18:265-276.

Geu-Flores, F., Møldrup, M. E., Böttcher, C., Olsen, C. E., Scheel, D., and Halkier, B. A. 2011. Cytosolic g-glutamyl peptidases process glutathione conjugates in the biosynthesis of glucosinolates and camalexin in Arabidopsis. Plant Cell 23:2456-2469.

Gigolashvili, T., Berger, B., Mock, H. P., Müller, C., Weisshaar, B., and Flügge, U. I. 2007. The transcription factor HIG1/MYB51 regulates indolic glucosinolate biosynthesis in Arabidopsis thaliana. Plant J. 50:886-901.

Glawischnig, E. 2006. The role of cytochrome P450 enzymes in the biosynthesis of camalexin. Biochem. Soc. Trans. 34:1206-1208.

Glawischnig, E. 2007. Camalexin. Phytochemistry 68:401-406.

Glawischnig, E., Hansen, B. G., Olsen, C. E., and Halkier, B. A. 2004. Camalexin is synthesized from indole-3-acetaldoxime, a key branching point between primary and secondary metabolism in Arabidopsis. Proc. Natl. Acad. Sci. U.S.A. 101:8245-8250.

Glazebrook, J. 2005. Contrasting mechanisms of defense against biotrophic and necrotrophic pathogens. Annu. Rev. Phytopathol. 43:205-227.

Grubb, C. D., and Abel, S. 2006. Glucosinolate metabolism and its control. Trends Plant Sci. 11:89-100.

Guzmán, P., and Ecker, J. R. 1990. Exploiting the triple response of Arabidopsis to identify ethylene-related mutants. Plant Cell 2:513-523.

Halkier, B. A., and Gershenzon, J. 2006. Biology and biochemistry of glucosinolates. Annu. Rev. Plant Biol. 57:303-333.

Hull, A. K., Vij, R., and Celenza, J. L. 2000. Arabidopsis cytochrome $\mathrm{P} 450$ s that catalyze the first step of tryptophan-dependent indole-3-acetic acid biosynthesis. Proc. Natl. Acad. Sci. U.S.A. 97:2379-2384.

Jefferson, R. A. 1987. Assaying chimeric genes in plants: the GUS gene fusion system. Plant. Mol. Biol. Rep. 5:387-405.

Kikuchi, K., Ueguchi-Tanaka, M., Yoshida, K. T., Nagato, Y., Matsusoka, M., and Hirano, H.-Y. 2000. Molecular analysis of the NAC gene family in rice. Mol. Gen. Genet. 262:1047-1051.

Lawton, K. A., Friedrich, L., Hunt, M., Weymann, K., Delaney, T., Kessmann, H., Staub, T., and Ryals, J. 1996. Benzothiadiazole induces disease resistance in Arabidopsis by activation of the systemic acquired resistance signal transduction pathway. Plant J. 10:71-82.

Loeffler, C., Berger, S., Guy, A., Durand, T., Bringmann, G., Dreyer, M.,

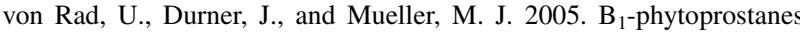
trigger plant defense and detoxification responses. Plant Physiol. 137:328-340

Lu, D. P., Wu, S. J., Gao, X. Q., Zhang, Y. L., Shan, L. B., and He, P. 2010. A receptor-like cytoplasmic kinase, BIK1, associates with a flagellin receptor complex to initiate plant innate immunity. Proc. Natl. Acad. Sci. U.S.A. 107:496-501

Mao, G., Meng, X., Liu, Y., Zheng, Z., Chen, Z., and Zhang, S. 2011. Phosphorylation of a WRKY transcription factor by two pathogenresponsive MAPKs drives phytoalexin biosynthesis in Arabidopsis. Plant Cell 23:1639-1653.

Melotto, M., Underwood, W., Koczan, J., Nomura, K., and He, S. Y. 2006. Plant stomata function in innate immunity against bacterial invasion. Cell 126:969-980.

Mersmann, S., Bourdais, G., Rietz, S., and Robatzek, S. 2010. Ethylene signaling regulates accumulation of the FLS2 receptor and is required for the oxidative burst contributing to plant immunity. Plant Physiol. 154:391-400.

Mikkelsen, M. D., Hansen, C. H., Wittstock, U., and Halkier, B. A. 2000. Cytochrome P450 CYP79B2 from Arabidopsis catalyzes the conversion of tryptophan to indole-3-acetaldoxime, a precursor of indole glucosinolates and indole-3-acetic acid. J. Biol. Chem. 275:3371233717.

Millet, Y. A., Danna, C. H., Clay, N. K., Songnuan, W., Simon, M. D., Werck-Reichhart, D., and Ausubel, F. M. 2010. Innate immune responses 
activated in Arabidopsis roots by microbe-associated molecular patterns. Plant Cell 22:973-990.

Morikawa, T., Mizutani, M., Aoki, N., Watanabe, B., Saga, H., Saito, S., Oikawa, A., Suzuki, H., Sakurai, N., Shibata, D., Wadano, A., Sakata, K., and Ohta, D. 2006. Cytochrome P450 CYP710A encodes the sterol C-22 desaturase in Arabidopsis and tomato. Plant Cell 18:1008-1022.

Nafisi, M., Goregaoker, S., Botanga, C. J., Glawischnig, E., Olsen, C. E., Halkier, B. A., and Glazebrook, J. 2007. Arabidopsis cytochrome P450 monooxygenase 71A13 catalyzes the conversion of indole-3acetaldoxime in camalexin synthesis. Plant Cell 19:2039-2052.

Ogata, Y, Sakurai, N., Suzuki, H., Aoki, K., Saito, K., and Shibata, D. 2009. The prediction of local modular structures in a co-expression network based on gene expression datasets. Genome Inf. 23:117-127.

Ogata, Y., Suzuki, H., Sakurai, N., and Shibata, D. 2010. CoP: a database for characterizing co-expressed gene modules with biological information in plants. Bioinformatics 26:1267-1268.

Olsen, A. N., Ernst, H. A., Lo Leggio, L., and Skriver, K. 2005a. DNAbinding specificity and molecular functions of NAC transcription factors. Plant Science 169:785-797.

Olsen, A. N., Ernst, H. A., Lo Leggio, L., and Skriver, K. 2005b. NAC transcription factors: structurally distinct, functionally diverse. Trends Plant Sci.10:79-87.

Ooka, H., Satoh, K., Doi, K., Nagata, T., Otomo, Y., Murakami, K., Matsubara, K., Osato, N., Kawai, J., Carninci, P., Hayashizaki, Y., Suzuki, K., Kojima, K., Takahara, Y., Yamamoto, K., and Kikuchi, S. 2003. Comprehensive analysis of NAC family genes in Oryza sativa and Arabidopsis thaliana. DNA Res. 10:239-247.

Petersen, K., Fiil, B. K., Mundy, J., and Petersen, M. 2008. Downstream targets of WRKY33. Plant Signal Behav. 3:1033-1034.

Qiu, J. L., Fiil, B. K., Petersen, K., Nielsen, H. B., Botanga, C. J. Thorgrimsen, S., Palma, K., Suarez-Rodriguez, M. C., SandbechClausen, S., Lichota, J., Brodersen, P., Grasser, K. D., Mattsson, O., Glazebrook, J., Mundy, J., and Petersen, M. 2008. Arabidopsis MAP kinase 4 regulates gene expression through transcription factor release in the nucleus. EMBO (Eur. Mol. Biol. Organ.) J. 27:2214-2221.

Ren, D., Liu, Y., Yang, K. Y., Han, L., Mao, G., Glazebrook, J., and Zhang, S. 2008. A fungal-responsive MAPK cascade regulates phytoalexin biosynthesis in Arabidopsis. Proc. Natl. Acad. Sci. U.S.A. 105:5638-5643.

Robatzek, S., Chinchilla, D., and Boller, T. 2006. Ligand-induced endocytosis of the pattern recognition receptor FLS2 in Arabidopsis. Genes Dev. 20:537-542.

Saitou, N., and Nei, M. 1987. The neighbor-joining method: a new method for reconstructing phylogenetic trees. Mol. Biol. Evol. 4:406-425.

Schuhegger, R., Nafisi, M., Mansourova, M., Petersen, B.L., Olsen, C. E. Svatoš, A., Halkier, B. A., and Glawischnig, E. 2006. CYP71B15 (PAD3) catalyzes the final step in camalexin biosynthesis. Plant Physiol. 141:1248-1254.

Sønderby, I. E., Burow, M., Rowe, H. C., Kliebenstein, D. J., and Halkier, B. A. 2010. A complex interplay of three R2R3 MYB transcription factors determines the profile of aliphatic glucosinolates in Arabidopsis. Plant Physiol. 153:348-363.
Su, T. B., Xu, J. A., Li, Y. A., Lei, L., Zhao, L., Yang, H. L., Feng, J. D., Liu, G. Q., and Ren, D. T. 2011. Glutathione-indole-3-acetonitrile is required for camalexin biosynthesis in Arabidopsis thaliana. Plant Cell 23:364-380.

Suarez-Rodriguez, M. C., Adams-Phillips, L., Liu, Y., Wang, H., Su, S.H., Jester, P. J., Zhang, S., Bent, A. F., and Krysan, P. J. 2007. MEKK1 is required for flg22-induced MPK4 activation in Arabidopsis plants. Plant Physiol. 143:661-669.

Tamura, K., Peterson, D., Peterson, N., Stecher, G., Nei, M., and Kumar, S. 2011. MEGA5: molecular evolutionary genetics analysis using maximum likelihood, evolutionary distance, and maximum parsimony methods. Mol. Biol. Evol. 69:A13.

Thordal-Christensen, H., Zhang, Z. G., Wei, Y. D., and Collinge, D. B. 1997. Subcellular localization of $\mathrm{H}_{2} \mathrm{O}_{2}$ in plants: $\mathrm{H}_{2} \mathrm{O}_{2}$ accumulation in papillae and hypersensitive response during the barley-powdery mildew interaction. Plant J. 11:1187-1194.

Tierens, K., Thomma, B., Bari, R. P., Garmier, M., Eggermont, K., Brouwer, M., Penninckx, I., Broekaert, W. F., and Cammue, B. P. A. 2002. Esa1, an Arabidopsis mutant with enhanced susceptibility to a range of necrotrophic fungal pathogens, shows a distorted induction of defense responses by reactive oxygen generating compounds. Plant J. 29:131-140.

Veronese, P., Nakagami, H., Bluhm, B., AbuQamar, S., Chen, X., Salmeron,

J., Dietrich, R. A., Hirt, H., and Mengiste, T. 2006. The membraneanchored BOTRYTIS-INDUCED KINASE1 plays distinct roles in Arabidopsis resistance to necrotrophic and biotrophic pathogens. Plant Cell 18:257-273.

Whalen, M. C., Innes, R. W., Bent, A. F., and Staskawicz, B. J. 1991. Identification of Pseudomonas syringae pathogens of Arabidopsis and a bacterial locus determining avirulence on both Arabidopsis and soybean. Plant Cell 3:49-59.

Wildermuth, M. C., Dewdney, J., Wu, G., and Ausubel, F. M. 2001. Isochorismate synthase is required to synthesize salicylic acid for plant defense. Nature 414:562-565.

Witkowski, D. A., and Halling, B. P. 1989. Inhibition of plant protoporphyrinogen oxidase by the herbicide acifluorfen-methyl. Plant Physiol. 90:1239-1242.

Zhang, J., Shao, F, Li, Y., Cui, H., Chen, L., Li, H., Zou, Y., Long, C. Lan, L., Chai J., Chen, S., Tang, X., and Zhou, J. M. 2007. A Pseudomonas syringae effector inactivates MAPKs to suppress PAMP-induced immunity in plants. Cell Host Microbe 1:175-185.

Zheng, Z. Y., Abu Qamar, S., Chen, Z. X., and Mengiste, T. 2006. Arabidopsis WRKY33 transcription factor is required for resistance to necrotrophic fungal pathogens. Plant J. 48:592-605.

\section{AUTHOR-RECOMMENDED INTERNET RESOURCES}

ATTED-II database: atted.jp

KAGIANA database: webs2.kazusa.or.jp/kagiana/indexjpn.html

Arabidopsis gene mapping tool: signal.salk.edu/cgi-bin/tdnaexpress

Gene Express Omnibus database: www.ncbi.nlm.nih.gov/geo

CoP database: webs2.kazusa.or.jp/kagiana/cop/index0906.html 